ISSN: 0514-7336 — ISSN electrónico: 2386-3943

DOI: https://doi.org/10.14201/zephyrus2020861542

\title{
ANÁLISIS TECNOTIPOLÓGICO Y CRONOLÓGICO DE LA INDUSTRIA LÍTICA SUPERFICIAL RECUPERADA EN LAS TERRAZAS DEL CAUCE DEL BAJO EBRO
}

\section{Techno-typological and chronological analysis of surface lithic industry recovered in terraces from the lower Ebro valley}

Ivan Gironès Rofes*, Miquel Molist Montaña* y Salvador Pardo-Gordó**

* Dpto. de Prehistòria. Univ. Autònoma de Barcelona. Edificio mRA. Campus de la UAB. 08193 Bellaterra (Barcelona).Correo-e: ivan.girones@e-campus.uab.cat; miquel.molist@uab.cat; ID ORCID: https://orcid.org/00000002-6924-0382; https://orcid.org/0000-0002-2212-4384

** Dpto. de Prehistòria, Arqueologia i Història Antiga. Univ. de València. C/ Blasco Ibáñez, 28. 46010 València. Correo-e: salvador.pardo@uv.es. ID ORCID: https://orcid.org/0000-0002-1060-1526

Recepción: 22/12/19; Revisión: 13/02/2020; Aceptación: 14/07/2020

Resumen: Los estudios focalizados en la Prehistoria Reciente peninsular han sido escasos en el cauce bajo del valle del Ebro (Tarragona). La investigación en esta área se caracteriza sobre todo por el estudio de los materiales recuperados en intervenciones arqueológicas de urgencia o bien en su inventario. Esto deriva en la emergencia de una problemática definida por una continua ausencia de interpretaciones válidas respecto a las dinámicas ocupacionales del territorio. Para poder analizar las dinámicas ocupacionales y cronoculturales, en este trabajo se presenta el análisis y estudio de varios conjuntos líticos procedentes de prospecciones no sistemáticas de cuatro áreas -Vall del Llop, La Conca, Vall de Mantons y Vall de Carrinya- desde una perspectiva morfo-tecno-tipológica. Se pretende poder establecer estimaciones cronológicas de los conjuntos y combinarlas con la observación off-site. Para ello el enfoque se basa en la aplicación de técnicas de modelización bayesiana que puedan aproximarnos al contexto espaciotemporal de los artefactos analizados.

Palabras clave: Prehistoria Reciente mediterránea; valle del Ebro; industria lítica; terrazas fluviales; conjuntos superficiales; tipología lítica.

Авsтract: Studies focused on Late Prehistory have been scarce in the lower Ebro valley (Tarragona). Research in this area is characterized by the study of materials recovered in archaeological salvage excavations or their inventory. This results in the problematic absence of valid interpretations regarding the occupational dynamics of the territory. To analyse the occupational and chrono-cultural dynamics, this work presents the review and study of various lithic assemblages from unsystematic surveys of four areas -Vall del Llop, La Conca, Vall de Mantons y Vall de Carrinya- from a morpho-techno-typological perspective. It is intended to be able to establish chronological estimates of the ensembles and combine them with off-site datasets. To do so, the approach is based on the application of Bayesian modelling techniques that can approximate the spatio-temporal context of the target artefacts.

Key words: Late Mediterranean Prehistory; Ebro valley; lithic industry; river terraces; surface assemblages; lithic typology.

Ediciones Universidad de Salamanca / 요 


\section{Introducción ${ }^{1}$}

El territorio catalán del bajo Ebro destaca por su importancia a lo largo de la historia debido a su posición geográfica estratégica, puesto que es un corredor natural que conecta el interior peninsular con la costa mediterránea. Sin embargo, este territorio ha sufrido numerosas transformaciones tanto naturales como antrópicas debido a su alta densidad de ocupación y reocupación. En el caso concreto de las ocupaciones humanas en momentos prehistóricos, aunque existe un ruido de fondo, no se ha desarrollado un trabajo de investigación sistemático, por lo que la información arqueológica disponible entre el Epipaleolítico y la Edad del Bronce -13400-4200 cal BP- es reducida y parcial.

A partir de la recuperación de artefactos líticos se visibilizan multitud de espacios abiertos. Entre estos, destacan las terrazas agrícolas, que permiten inferir actividades humanas. Los movimientos que afectan al terreno posibilitan la documentación de numerosas concentraciones de artefactos descontextualizados estratigráficamente. Esta situación crea una desavenencia de casos de estudio que abarca una multitud de artefactos provenientes de palimpsestos, los cuales debido a la ausencia de contexto arqueológico tienden a la reducción de su potencialidad analítica y a una menor integridad en la información arqueológica.

Sin embargo, la presencia de tales conjuntos puede guiar hacia la evidencia de varios tipos de actividad regional interconectada en diferentes redes. La gran variedad de niveles de ocupación del territorio -tanto cronológica como espacial- puede ser identificada con relación al estudio de dicho

1 Los autores son miembros del Grup de Recerques Arqueològiques al Mediterrani i Pròxim Orient (GRAMPO). La realización de este trabajo ha sido posible gracias a la ayuda de los miembros del sappo-grampo. Agradecemos la colaboración imprescindible para su desarrollo y la dedicación a este trabajo de M. Pla, J. M. Pros y al Museu de les Terres de l'Ebre por permitir acceder y facilitar el estudio del material arqueológico. El trabajo ha contado con fondos de l'agaur para Grups de Recerca Consolidats -Grampo, ref: 2017-sGR-1302- y la financiación de la Generalitat de Catalunya (Expedientes 2014/100633 y CLT 2018/00035). material o, paralelamente, trasladando el análisis off-site al contexto arqueológico documentado. En esta línea, se pretende abordar la exposición de diferentes puntos territoriales dentro de la región del área catalana del valle del Ebro con presencia de conjuntos líticos descontextualizados, vinculables a la Prehistoria Reciente mediterránea peninsular. Dentro del registro de las terrazas como puntos de potencialidad arqueológica o áreas con expectativa prehistórica, se indagará sobre la dualidad conceptual que supone el estudio de los conjuntos superficiales.

Para ello, en la primera parte del trabajo presentaremos el material recuperado en varias áreas de expectativa arqueológica situadas en los municipios de Aldover y Xerta (Baix Ebre, Tarragona). A continuación, se presentará la muestra estudiada y su correspondiente análisis morfo-tecno-tipológico de las terrazas seleccionadas: la Vall del Llop, Vall de Mantons, La Conca y Vall de Carrinya. Finalmente, realizaremos una aproximación cronocultural no lineal aplicando la inferencia bayesiana e integraremos nuestros resultados a escala regional.

\section{Definición espacial y contextualización arqueológica}

La actual presión agrícola, centrada en el extremo de la depresión del Ebro, ha modificado el paisaje afectando las terrazas del Holoceno superior. Estas formaciones fluviales rodean y delimitan el curso acuático, extendiéndose como llanuras sedimentológicamente formadas por acumulaciones de arenas, gravas y limos. Colindantes a estas formaciones holocénicas yacen las estratigrafías más antiguas, pertenecientes a áreas aluviales del Pleistoceno Superior. En definitiva, esta formación manifiesta la dualidad entre las llanuras aluviales más próximas al río con las montañas circundantes, delimitadas por el paraje natural de la Serra del Cardo, entre Serra de Pàndols i Cavalls, Serra de Tivissa y Els Ports. Esta orografía determina diferentes medios de ocupación y aprovechamiento de recursos en el mismo territorio. 


\begin{tabular}{|l|c|c|c|c|c|}
\hline \multicolumn{1}{|c|}{ Yacimiento } & Muestra & Material & BP & CAL BP & ReferenCia \\
\hline Cova Clot de l'Hospital & OxA-16421 & hueso & $11115 \pm 50$ & $13129-12892$ & Bosch, 2016 \\
\hline Cova Clot de l'Hospital & OxA-16572 & hueso & $10045 \pm 45$ & $11732-11416$ & ibidem \\
\hline Cova del Vidre & Beta-58933 & carbón & $10740 \pm 130$ & $12842-12548$ & ibidem \\
\hline Cova del Vidre & UBAR-832 & carbón & $7290 \pm 70$ & $8174-8037$ & ibidem \\
\hline Cova del Vidre & Beta-58934 & carbón & $6180 \pm 90$ & $7195-6965$ & ibidem \\
\hline Cova del Vidre & OxA-26064 & hueso & $6181 \pm 35$ & $7144-7028$ & ibidem \\
\hline Cova del Vidre & OxA-26065 & hueso & $6248 \pm 33$ & $7238-7161$ & ibidem \\
\hline Barranc d'en Fabra & Beta-61490 & carbón & $5880 \pm 110$ & $6845-6568$ & Bosch et al., 1996 \\
\hline
\end{tabular}

FIG. 1. Dataciones disponibles de los contextos referentes regionales de la cuenca inferior del Ebro.

Las evidencias arqueológicas en esta región, aunque no estudiadas en detalle, son notorias. El material arqueológico superficial aflora en multitud de espacios que se sitúan dentro de esta dualidad geológica. En este sentido, tanto contextos arqueológicos en cueva como en terrazas fluviales quedan totalmente afectados por diferentes procesos posdeposicionales -antrópicos y/o naturales-. Esta situación en espacios abiertos no permite determinar con fiabilidad la presencia de hábitat. Históricamente estas acumulaciones líticas superficiales han sido definidas como talleres de superficie debido a la ausencia de estructuras de hábitat/producción asociadas al material (Vilaseca, 1936). A tenor de sus trabajos centrados tanto en el Camp de Tarragona, el Baix Ebre y el Priorat, Vilaseca (1936, 1939, 1953, 1973) reforzó dicho concepto, el cual ha sido corroborado a raíz de diferentes intervenciones arqueológicas de urgencia en la cuenca baja del Ebro (Esteve-Gálvez, 1954, 1966, 2000; Genera, 1992). Aun con la existencia de la disociación de material en torno a la espacialidad y temporalidad y, por ende, a la interpretación social y productiva de los artefactos, algunos paralelos regionales sirven de referentes para una primera aproximación a la configuración del hábitat y de las actividades realizadas (Fig. 1). A tal efecto, algunos yacimientos con niveles de ocupación válidos evidencian, en relación con las cronologías tratadas en este trabajo, un hábitat al aire libre como El Molló (Piera et al., 2016) y Barranc d'en Fabra (Bosch et al., 1996: 55). Paralelamente, en la región se han documentado ocupaciones en cueva con secuencias amplias o puntuales. Por un lado, Cova del Vidre presenta una secuencia dividida en 3 fases: la primera, desde el Epipaleolítico de industria Microlaminar -1284212548 cal вр-; una segunda fase de ocupación con industrias vinculadas con el Mesolítico Geométrico de facies Cocina -8174-8037 cal вр-; y la fase más reciente documentada como Neolítico Antiguo Cardial -7238-7138 cal вр-2 ${ }^{2}$. Esta última comparte paralelos con la industria lítica de los yacimientos vecinos del Bajo Aragón, como Botiquería dels Moros (Barandiarán, 1978), Costalena (Barandiarán y Cava, 1989), Abric del Pontet (Mazo y Montes, 1992) o Abric de Secans (Rodanés et al., 1996; en Bosch, 2011). Por otro lado, la Cova del Clot de l'Hospital, localizada en la misma sierra, se adscribe culturalmente al llamado Epimagdaleniense, a raíz del material recuperado en diferentes intervenciones y revisiones (Bosch et al., 2016; Esteve-Gálvez, 2000; Genera, 1984-1985).

Tal dualidad de ocupaciones remite a una multiplicidad de actividades y un mayor grado de conservación de los niveles arqueológicos en cueva, donde los procesos postdeposicionales presentan un grado menor de afectación. Esto ha permitido que se documenten tanto ocupaciones eventuales como inhumaciones en las cavidades. En este sentido debe destacarse el conjunto de Coves de l'Aumediella -Benifallet- (Colominas, 1922; Molist et

2 Bosch, J.: El procés de neolitització a la regió del curs inferior de l'Ebre. Tesis doctoral inédita presentada en 2005 en la Univ. de Barcelona. 
al., 2016a). Enfatizamos, dentro de este complejo de cavidades, la Cova Xafarroques, donde fuentes orales indican la existencia de una inhumación de varios individuos (Molist et al., 2016a: 82) y multitud de recipientes cerámicos característicos de la Edad del Bronce Inicial y Medio, los cuales han sido recientemente estudiados ${ }^{3}$. Del mismo modo, la revisión de la Cova del Calvari -Amposta- ha permitido definir un contexto funerario caracterizado por la presencia de objetos de metal -puro o arsenical- y cerámicas campaniformes (Soriano et al., 2016). Otros yacimientos de índole similar son la Cova Cervereta -Vinallop-Tortosa- (Forcadell y Villalbí, 1999) o Masdenvergenc ${ }^{4}$, entre otros.

Finalmente, otras áreas con evidencias sepulcrales y de gran potencialidad se localizan sobre las terrazas del Ebro, como es el conjunto del Molinàs. Con 83 estructuras funerarias, comprenden cronologías entre el Neolítico Antiguo Epicardial hasta el Neolítico Medio. En este rango temporal, se asocian estructuras de tipo cista con presencia de recipientes cerámicos de estilo Montboló, Molinot en menor medida y las del Neolítico Medio con vasos carenados bitroncocónicos, con paralelos en el área del noreste peninsular pertenecientes a los llamados 'sepulcros de fosa' (Bosch et al., 2000:11; Molist et al., 2016b).

\section{Metodología}

\subsection{Categorización litica}

El análisis de los artefactos líticos se ha llevado a cabo desde una perspectiva morfo-tecno-tipológica, es decir, su estudio a partir de la categorización tipológica teniendo en cuenta la descontextualización

3 Vicens, L. V.: Aproximación de las producciones cerámicas del Neolitico Final-Bronce Medio en el tramo bajo del rio Ebro: estudio a partir del conjunto de las cuevas de l'Aumediella. Trabajo Final de Grado presentado en 2018 en la Univ. Autònoma de Barcelona.

4 Bosch, J.: El procés de neolitització a la regió del curs inferior de l'Ebre. Tesis doctoral inédita presentada en 2005 en la Univ. de Barcelona. de los conjuntos anteriormente mencionada. Partimos de los conceptos y definiciones tecnológicas de Bordes (1961) y Laplace (1974), junto con autores que reformulan la utilización de tales nomenclaturas definitorias y su traslado a las formas productivas como la recopilación metodológica de Merino (1994), Binder (1987), Juan-Cabanilles (2008) y Palomo (2012) para los retocados y la definición de los núcleos. Utilizamos principalmente los criterios de Juan-Cabanilles (2008) y Fortea (1973) exclusivamente para la definición tecno-tipológica y la metodología de categorización jerárquica, aplicada al Epipaleolítico mediterráneo y adaptada a los períodos considerados: desde el Epipaleolítico a la Edad del Bronce.

La categorización a partir de la definición morfotecno-tipológica se rige bajo un precepto jerárquico definido por Binder (1987), en nuestro caso utilizando el establecido por J. Cabanilles (2008) y readaptando su estructura a nuestros conjuntos analizados. Por ende, partimos de la definición que establezca una mayor aproximación cronológica tanto en presencia como ausencia de características morfo-tecno-tipológica que se encuentren configuradas en el conjunto lítico. Consiguientemente, tenemos en cuenta el mayor nivel de complejidad morfo-tecno-tipológica del tipo conceptualizado, en vínculo con la mayor especificación o relación cronológica que se presenta extrayacimiento. $\mathrm{Su}$ desarrollo se implementa a partir de la observación de distintos criterios, principalmente, el retoque, los aspectos morfológicos y tipométricos en diversos niveles de profundidad (Fig. 2):

- Tipologías primarias: corresponden a las tipologías configuradas según cierta variabilidad y combinatoria técnica, dando un nivel alto de complejidad respecto a los tres criterios observados -siendo la combinación de dos o más técnicas las cuales definan una morfología y diseño propios de cierto período productivo concreto-.

- Tipologías secundarias: se componen por un menor nivel de combinación técnica y, por extensión, de complejidad, pertenecientes a un rango cronológico más amplio. 


\begin{tabular}{|c|c|c|}
\hline $\begin{array}{l}\text { NiVEL } \\
\text { TIPOLÓGICO }\end{array}$ & MORFOTECNIA ESPECÍFICA & Tipo asociado \\
\hline \multirow{8}{*}{ PRIMARIO } & morfología foliácea por retoque plano bifacial & punta de proyectil \\
\hline & morfología subfoliácea por retoque plano unifacial/bifacial & esbozo o preforma foliácea \\
\hline & denticulación regular & dientes de hoz \\
\hline & $\begin{array}{l}\text { bitruncatura simple lateral o } \\
\text { dorso curvado perfilando forma geométrica }\end{array}$ & geométrico \\
\hline & apuntamiento bilateral por retoque abrupto & perforador \\
\hline & muesca y faceta de golpe de microburil & microburil \\
\hline & frente de raspador (semi/circular + retoque abrupto) & raspador \\
\hline & hoja lateral activa con retoque simple & raedera \\
\hline \multirow{6}{*}{ SECUNDARIO } & retoque plano o sobreelevado lateral sobre soporte laminar & $\begin{array}{l}\begin{array}{l}\text { lámina de retoque plano o } \\
\text { sobreelevado }\end{array} \\
\end{array}$ \\
\hline & borde abatido o dorso por retoque abrupto & lámina de dorso \\
\hline & frente por retoque abrupto o truncatura (fractura retocada) & truncatura \\
\hline & $\begin{array}{l}\text { escotadura o abatimiento parcial oblicuo proximal y/o } \\
\text { distal sobre soporte laminar }\end{array}$ & lámina de base estrecha \\
\hline & muesca o denticulación irregular & muesca/denticulado \\
\hline & faceta de golpe de buril & buril \\
\hline \multirow{3}{*}{ TERCIARIO } & retoque marginal sobre soporte laminar & lámina de retoque marginal \\
\hline & retoque sobre soporte de lasca & lasca retocada \\
\hline & embotadura o retoque no sistemático producidos por el uso & piezas con filo embotado \\
\hline
\end{tabular}

FIG. 2. Tabla de categorización utilizada para la jerarquización morfo-tecno-tipológica litica (a partir de Juan-Cabanilles, 2008). La asignación jerárquica se establece a partir del mayor nivel de complejidad morfo-tecno-tipológica y de su acotación cronológica (de arriba abajo).

- Tipologías terciarias: hacen referencia a piezas de nivel genérico, poca presencia técnica o un nivel de tecnicidad productiva muy común respecto al resto de artefactos. Mayoritariamente nos referimos a tipos de soporte definidos por el retoque y morfológica y cronológicamente poco significativos.

\subsection{Aproximación cronológica probabilistica}

La determinación tipológica a través de los aspectos morfotécnicos definidos nos servirá de base para la construcción del modelo probabilístico. La aplicación de este tipo de modelos en otros contextos -véanse principalmente los trabajos de modelización radiométrica de Buck y Juárez (2017), Buck y Litton (1991), Buck y Sahu (2000), Bayliss et al. (2007), Bayliss (2009), entre otros- requiere de una integración de datos de referencia de distinta naturaleza. En torno a los modelos empíricos bayesianos, su utilización y desarrollo se basan en la construcción de modelos complejos que parten de distintas realidades, simplificándose a través de una perspectiva inductiva (Barton, 2013: 154). Con ello, se adhiere información generada a priori, la cual parte ya de una muestra existente, utilizada para realizar una estimación a otros conjuntos de datos. Esta permite un aumento de precisión en los resultados y una reducción considerable del error estándar y de varianza (Robertson, 1999: 139). El motivo por el que hemos adoptado una perspectiva bayesiana para el análisis de las colecciones superficiales reside en ir más allá de las pruebas de Hipótesis Nula, puesto que los métodos bayesianos adoptan una simplicidad a nivel interpretativo sin caer en la confusión de la $\mathrm{H}_{0}-\mathrm{y}$, por ende, evitar los errores de tipo I y II-. Es decir, la inferencia bayesiana obtiene resultados 
sobre la probabilidad de hipótesis de acuerdo con los datos a priori (Otárola-Castillo y Torquato, 2018).

Teniendo en cuenta las diferentes ramificaciones que se desprenden de los modelos empíricos bayesianos, en particular nos centraremos en los métodos clasificatorios probabilísticos derivados del Nä̈ve Bayes Classifier. Definido y aplicado en diferentes contextos (Robertson, 1999; Barton, 2013; Ortman, 2016; Ortman et al., 2007), consiste en la simplificación de la información a priori a partir de la probabilidad condicional del Teorema de Bayes. La reformulación de este teorema y su simplificación permiten introducir la información previa a un modelo cualitativo, el cual conduce a datos probabilísticos significativos con el objetivo de obtener información desconocida (Thoeming, 2016: 194; Kuhn y Johnson, 2013; Aggarwal, 2015: 306).

Las aproximaciones a la cronología de las colecciones superficiales a partir de aplicaciones estadísticas han sido una línea explorada en las comarcas centro-meridionales del País Valenciano (Barton et al., 1999, 2002, 2004; Bernabeu et al., 2001; Pardo-Gordó et al., 2009, 2015; Snitker et al., 2018), realizadas a través de la construcción de rangos probabilísticos de menor a mayor resolución cronocultural sobre la dicotomía presencia-ausencia. Sin embargo, será el trabajo de J. Fernández-López de Pablo y C. M. Barton (2013) el que aplica la estadística bayesiana en la Península Ibérica para dotar de cronología a diferentes colecciones superficiales. Esta aproximación permite la asignación cronológica sin perder la esencia de su multidimensionalidad, es decir, evitar las adscripciones cronoculturales absolutas o cronologías con justificaciones poco precisas.

Esta propuesta parte de unos datos previos que sirven como base para la obtención de los resultados y poder comprobar el rango -mayor o menor- de posibles eventos sucesorios de los conjuntos descontextualizados con mayor precisión. Al ser acumulativos, permiten cierta facilidad en la incorporación de nuevos datos actualizando la información a priori. La construcción del modelo clasificatorio probabilístico radica en la división de los datos en distintas fases de organización. De acuerdo con las fases cronoculturales de amplia aceptación - por ej., Neolítico antiguo- se designan varios criterios para su construcción:

Fase I: Selección. Los datos a priori se seleccionan a partir de la muestra arqueológica disponible. Por lo tanto, se enfatiza la relación cronocultural entre datos ya existentes que permitirán la definición cronológica y los niveles de fiabilidad y rigurosidad del modelo probabilístico. Para el desarrollo e incorporación de los datos, se adhieren tres aspectos fundamentales: estratigrafía, artefactos arqueológicos y dataciones radiométricas.

Fase II: Construcción. Hace referencia a la transformación de los datos obtenidos en la fase anterior, dando, por cada uno de los artefactos definidos, un valor probabilístico -entre 0-1- con relación al rango cronológico. De esta forma se evidencia la multieventualidad de los artefactos a través de resultados acumulativos. El tratamiento de los datos de la Fase II como de la Fase III -a continuación- se ha realizado utilizando el software estadístico $\mathrm{R}$ (Core Team, 2018) y más en concreto el script publicado en Bernabeu y colegas (2017). El resultado de este proceso es una tabla probabilística entre clase de artefacto y rango cronocultural.

Fase III: Aplicación. Los resultados de los datos a priori pasarán a ser la base de la aplicación del modelo a los casos de estudio. En este punto, ya se presenta la especificación cronocultural de los tipos de artefactos definidos de acuerdo con los datos referentes de la Fase I. Asimismo, fijamos los artefactos del caso de estudio de acuerdo con los rangos probabilísticos cronológicos de los palimpsestos.

La información compilada se ha adaptado a la propuesta de Fernández-López de Pablo y Barton (2013). Estos categorizan el análisis de los artefactos significativos distribuidos en 28 tipos de puntas de proyectil, desde laminitas de dorso y geométricos hasta puntas bifaciales. Estas clases son utilizadas para confeccionar un modelo regional basado en los datos disponibles de diversos yacimientos del área mediterránea peninsular, con un total de 35 contextos referentes -desde el NE peninsular hasta el área centromediterránea-, comprendidos 
cronoculturalmente entre el Epipaleolítico y el Campaniforme $-13400-4200$ cal BP-. En nuestra aproximación se han incrementado tanto los conjuntos analizados como los yacimientos de referencia. La descripción detallada de cada uno de ellos excede los objetivos de este trabajo, por lo que remitimos al trabajo de Gironès et al. (2020) donde se detalla y se discute dicha muestra.

\section{Estudio de caso: las áreas de potencialidad arqueológica}

Las terrazas con potencial arqueológico se localizan a lo largo del eje del río. Estas presentan una concentración $\mathrm{N}-\mathrm{s}$, la cual se reduce a medida que nos alejamos del Ebro. Tal y como se ha indicado en la introducción, en este trabajo nos centraremos en dos focos localizados en las poblaciones de Aldover y $\mathrm{Xerta}^{5}$ (Fig. 3):

- La zona norte, comprendida entre las terrazas delimitadas por la Serra del Rovelló, Lo Tormo, Serra de la Fatarella y la formación montañosa que configura el estrecho del Pas de l'Ase. El registro de las áreas de la zona norte es definido por varios trabajos centrados en la localización de yacimientos de superficie y una breve exposición de las características del conjunto (Vilaseca, 1953), incluyendo la revisión del material y algunas prospecciones (Genera, 1982, 1992). Junto a la gran cantidad de yacimientos documentados en algunas intervenciones programadas o de urgencia clasificados cronológicamente entre la Edad del Bronce y el Ibérico Final -Assut de Tivenys, Sant Miquel, Cova del Ximo, Lo Tossal, La Bruixeta, Aixalelles, Roca de l'Ortiga, Roca del Sol, Los Mallols, Ceviques, Racó de l'Aixerí y l'Assut, entre otros-, se documentan,

5 Debemos remarcar que la presencia de los focos mencionados se debe a varios factores posiblemente vinculados tanto a la accesibilidad de los campos para las tareas de prospección por parte del prospector, como también por la proximidad a los núcleos urbanos. Aun así, su definición se basa en el área total donde se hallan los artefactos arqueológicos y su concentración en número. por otra parte, las áreas con artefactos líticos en superficie, las cuales en la actualidad son de uso agrícola -Partida de Vuitenes-Rengs-Quadro, Los Plans, Les Canelles, Partida del Jardins-Gorraptes, Les Obagues, Pla de Carreres, Els Rabadans y Sepiello-. Sin embargo, estas áreas de potencialidad arqueológica comparten una posible multiplicidad cronológica en sus conjuntos. A estas concentraciones debemos incorporar los conjuntos de Pedra-Fita, Cova dels Cremats-Barranc de l'Aigua, documentados por vecinos de la zona (Fig. 4A у в).

- La zona sur, situada también en el valle, y más concretamente entre la Serra de Cardó y Els Ports. La información de concentraciones de material superficial ha sido constatada a partir de diferentes intervenciones arqueológicas (Genera, 1992) (Fig. 4C y D). En este sentido, aquellas áreas con mayor potencialidad -Conca y Vall del Llop- fueron objeto de una prospección sistemática, pero con resultados negativos (Genera, 1992). En esta zona, la información más actualizada proviene de las diferentes intervenciones arqueológicas asociadas a la construcción de infraestructura viaria. Estas han documentado asentamientos de cronología protohistórica (Les Valletes -Ibérico Pleno- y Lo Tossal -Bronce Final III-Primera Edad del Hierro-), pero también destacamos la intervención de prospección y excavación de la Vall de Mantons. Esta ha permitido registrar varias estructuras asociadas a la Edad del Bronce Final-Primera Edad del Hierro, matizando la cronología obtenida a partir de los artefactos encontrados en superficie, los cuales retrotraían su cronología.

\subsection{Estudio de caso: terrazas de la Zona s: Aldover-Xerta}

Las terrazas estudiadas se encuentran sobre el abanico aluvial transportado por el río, el cual ha formado terrazas originadas desde el Pleistoceno Superior que superan los $10 \mathrm{msnm}$. Sedimentológicamente se componen de gravas y lutitas, difiriendo 
del valle fluvial de formación más reciente -hasta el Holoceno- que comprende hasta $10 \mathrm{msnm}$. Nuestro análisis se centra en diferentes terrazas que

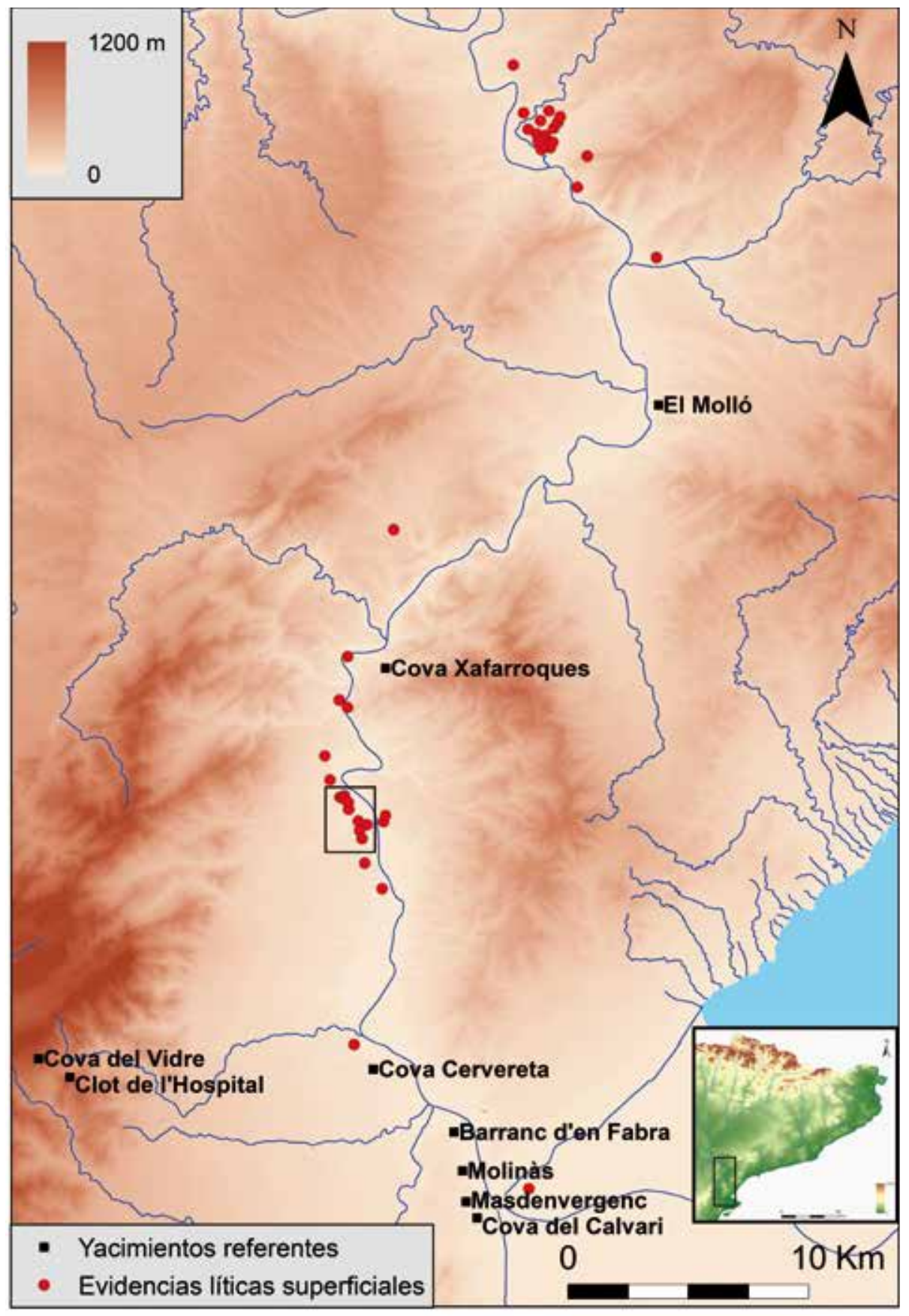

FIG. 3. MDE y localización de las áreas de expectativa con evidencias liticas superficiales y yacimientos referentes regionales mencionados con cronología neolitica (fuente: ICGCl IGN). El cuadro indica las concentraciones analizadas en este trabajo. forman parte del complejo aluvial con altitudes que oscilan generalmente entre los 20-50 msnm -Vall del Llop y La Conca- y los 50-60 msnm -Vall de Carrinya y Vall de Mantons-. Estas áreas se distribuyen de forma lineal siguiendo el eje del valle holocénico y delimitándose con este en eje N-S:

- Vall del Llop: localizada entre el Barranc de la Vall del Llop y Les Planetes, se considera una de las más extensas de las áreas tratadas, con 5 ha de superficie. Se caracteriza por una subdivisión de parcelas actualmente con cultivo arborícola y afectada por la construcción viaria.

- La Conca: la más extensa, con un área total de 5,42 ha, sobre diferentes terrazas contiguas. Separada por la misma construcción viaria como en la Vall del Llop, se extiende alrededor del Barranc de la Vall de La Conca, localizada más al sur. Actualmente está afectada por el multicultivo arborícola -generalmente de frutos y olivos- en contraste con el matorral de las vertientes (Genera, 1992).

- Vall de Carrinya: a 200 $m$ de la zona urbanizada, localizada entre 
A

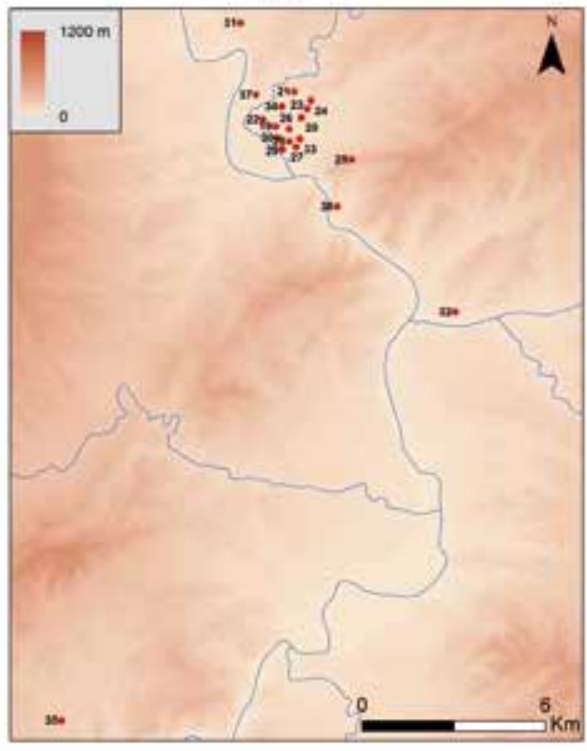

$\mathrm{C}$

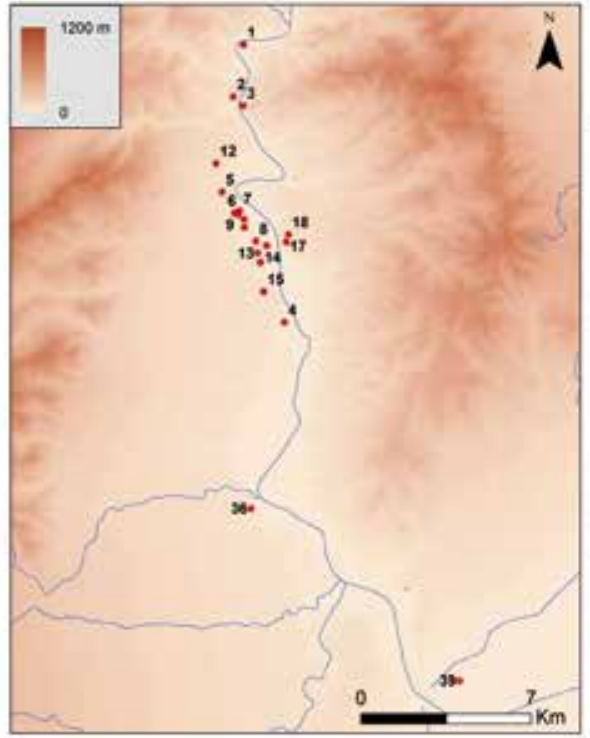

B

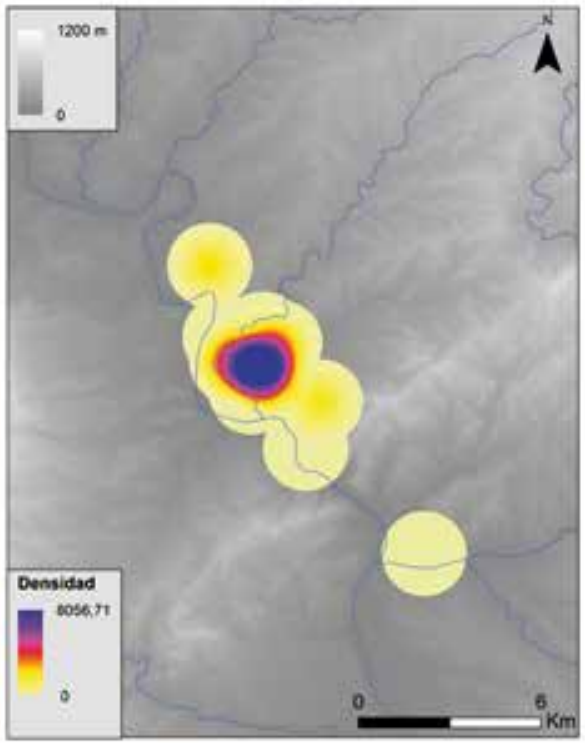

D

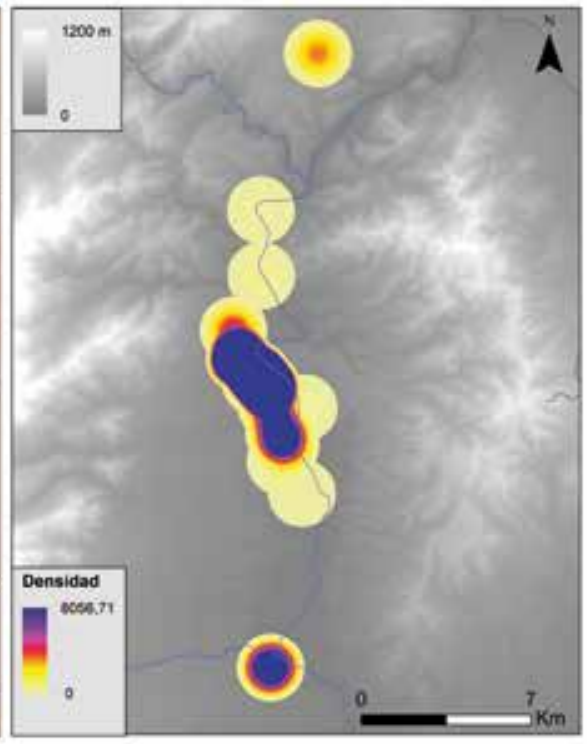

Fig. 4. A) Localización de las terrazas con evidencias líticas superficiales de la zona $N$ a partir de documentos originales de J. $M$. Pros: 19. Los Rengs; 20. Los Plans; 21. Les Canelles; 22. Els Jardins-Gorraptes; 23. Cap del Pla; 24. La Bruixeta; 25. Les Obagues; 26. Les Vuitenes; 27. Les Aumedines; 28. Los Mallols; 29. Freixinals; 30. Les Sorts; 31. Les Planes; 32. Pla de Carreres; 33. Rabadans; 34. Sepiello; 35. Cova del Ximo; 37. La Pedra-Fita; 38. Cova dels Cremats (exterior); B) densidad kernel del número de artefactos recuperados por J. M. Pros de la zona $\mathrm{N}_{\text {por }} \mathrm{km}^{2}$; C) Localización de las terrazas con evidencias liticas superficiales de la zona S a partir de documentos originales de E. Pla: 1. Potenti; 2. L'Assut; 3. Coll de Som; 4. Casa Blanca; 5. Els Estrets; 6-7. Vall del Llop; 8. El Tossal; 9. La Conca-Vall del Llop; 10. La Conca-El Tossal; 11. La Manigeta; 12. Gasolinera Xerta (Partida de Cogull); 13. Vall de Carrinya; 14. Vall de Mantons; 15. Fabra; 16. La Conca; 17-18. La Granja (I-II); 36. Pla de les Sitges; 39. Cuba. D) Densidad kernel a partir del número de artefactos s por $\mathrm{km}^{2}$ recuperados por E. Pla (fuente: ICGC). 
el Barranc dels Triadors y la Vall de Mantons, se unen en la partida Els Triadors. El conjunto procede de algunas terrazas separadas, todas ellas actualmente con cultivo de olivar. Se extienden en un total de 6,79 ha, distribuidas en tres terrazas de extensión variable $-3,96$ ha, 2,37 ha y 0,46 ha-.

- Vall de Mantons: ocupa una extensión de 1,9 ha y está delimitada por la Vall de Carrinya al norte y el Pla de les Illes hacia el sur e interior -o-. Se trata de una colina de $55 \mathrm{msnm}$ de media delimitada por el barranco de este mismo topónimo, actualmente destinado al cultivo de olivar en contraposición al bosque de pinar más interior.

\section{Análisis de los conjuntos}

\subsection{Datos arqueológicos disponibles y muestreo}

El material estudiado se localiza en la zona sur, ascendiendo a un total de 29.923 artefactos arqueológicos documentados por E. Pla en 18 áreas. La documentación del material se realizó a partir de un registro exhaustivo mediante su identificación. Por norma, la recuperación del material superficial se desarrolló durante los períodos de labrado del campo -comunicación personal de M. Pla-. Paralelamente a la identificación, procedieron a codificar e inventariar cada ítem registrando así la procedencia y el mes/año de recuperación -indicado en los documentos originales de E. Pla-. Debido a la cantidad ingente de material arqueológico, se han seleccionado 4 de las 18 áreas de expectativa arqueológica para realizar esta primera aproximación cronológica y tipológica. Esta selección se ha basado en criterios cuantitativos y cualitativos. El conjunto lítico muestreado para el presente estudio asciende a un total de 1.511 artefactos procedentes de las terrazas linealmente distribuidas por el eje del cauce fluvial, pertenecientes a las áreas descritas en el apartado anterior (Fig. 5).

\subsection{Resultados del análisis morfo-tecno-tipológico del conjunto}

La categorización lítica resultante del total de los 4 conjuntos nos da una visión global del contenido de la muestra analizada (Fig. 6). La jerarquización categórica a escala cuantitativa nos proporciona tres agrupaciones principales con el total de 18 categorías -incluyendo núcleos y fragmentos de estos- y hasta 5 agrupaciones con la partición del clúster. En una primera exploración de los resultados del análisis jerárquico deben destacarse los geométricos, ya que los considera como la clase de útil más distante de toda la muestra. En esta aproximación de conglomerados -utilizando el método UPGMA- se presentan los diferentes útiles de fondo en las primeras agrupaciones cuantitativas -truncaduras, muescas/ denticulados, raspadores y perforadores-. Un tercer grupo está formado, mayoritariamente, por aquellos restos sobre soporte laminar -microburiles y láminas de retoque plano-, exceptuando las lascas retocadas. Finalmente, la cuarta agrupación corresponde a un grupo de restos heterogéneos, sumándole cierta modificación de las divisiones entre los grupos 4 y 5 . Pertenecen en su mayoría a producciones de fondo, exceptuando las puntas bifaciales y dientes de hoz que resultan significativos a nivel espaciotemporal, pero poco destacados a nivel de muestra. Tanto en la prueba UPGMA como en el método Ward, ambos a partir de la distancia Euclídea, nos da una coincidencia jerárquica unánime (Fig. 7).

\subsubsection{Vall del Llop}

Dentro de los conjuntos analizados, la Vall del Llop presenta una gran variabilidad de producciones

\begin{tabular}{|l|c|c|c|}
\hline \multicolumn{1}{|c|}{ Área } & N. ${ }^{\text {Total }}$ & Muestra & \% Muestra \\
\hline La Conca & 7942 & 637 & 8,02 \\
\hline Vall del Llop & 9631 & 640 & 6,65 \\
\hline Vall de Mantons & 566 & 131 & 23,14 \\
\hline Vall de Carrinya & 958 & 103 & 10,75 \\
\hline
\end{tabular}

Fig. 5. Tabla de cantidad de material lítico asociado y proporciones de muestra analizadas en el estudio. 


\begin{tabular}{|c|c|c|c|c|c|c|c|c|}
\hline \multirow{2}{*}{ TeCnotipología } & \multicolumn{2}{|c|}{ Vall del Llop } & \multicolumn{2}{|c|}{ La Conca } & \multicolumn{2}{|c|}{ Vall de Mantons } & \multicolumn{2}{|c|}{ VALL DE CARRINYA } \\
\hline & $n$ & $\%$ & $n$ & $\%$ & $n$ & $\%$ & $n$ & $\%$ \\
\hline PUNTAS DE PROYECTIL BIFACIALES & 27 & 4,25 & 37 & 5,81 & 5 & 3,82 & 16 & 15,53 \\
\hline punta con aletas y pedúnculo & 7 & 25,93 & 21 & 56,76 & 0 & 0,00 & 8 & 50,00 \\
\hline punta triangular & 0 & 0,00 & 0 & 0,00 & 0 & 0,00 & 0 & 0,00 \\
\hline punta romboidal & 2 & 7,41 & 1 & 2,70 & 0 & 0,00 & 0 & 0,00 \\
\hline punta foliforme & 0 & 0,00 & 4 & 10,81 & 0 & 0,00 & 1 & 6,25 \\
\hline punta de base ensanchada & 0 & 0,00 & 1 & 2,70 & 0 & 0,00 & 0 & 0,00 \\
\hline punta de base estrecha & 0 & 0,00 & 0 & 0,00 & 0 & 0,00 & 0 & 0,00 \\
\hline punta de base cóncava o aletas & 1 & 3,70 & 0 & 0,00 & 0 & 0,00 & 0 & 0,00 \\
\hline punta de apéndice lateral & 0 & 0,00 & 0 & 0,00 & 0 & 0,00 & 1 & 6,25 \\
\hline punta de muescas laterales & 1 & 3,70 & 4 & 10,81 & 0 & 0,00 & 0 & 0,00 \\
\hline punta asimétrica & 0 & 0,00 & 0 & 0,00 & 0 & 0,00 & 0 & 0,00 \\
\hline fragmento de pedúnculo & 6 & 22,22 & 0 & 0,00 & 4 & 80,00 & 3 & 18,75 \\
\hline fragmento de armadura & 10 & 37,04 & 6 & 16,22 & 1 & 20,00 & 3 & 18,75 \\
\hline DiENTES DE HOZ & 16 & 2,52 & 33 & 5,18 & 3 & 2,29 & 3 & 2,91 \\
\hline bitruncatura & 2 & 12,50 & 3 & 9,09 & 0 & 0,00 & 0 & 0,00 \\
\hline truncatura + dorso & 2 & 12,50 & 0 & 0,00 & 2 & 66,67 & 2 & 66,67 \\
\hline bitruncatura + dorso & 10 & 62,50 & 2 & 6,06 & 0 & 0,00 & 1 & 33,33 \\
\hline sin abatimiento & 2 & 12,50 & 1 & 3,03 & 1 & 33,33 & 0 & 0,00 \\
\hline Preformas/esbozos foliáceos & 18 & 2,83 & 45 & 7,06 & 2 & 1,53 & 14 & 13,59 \\
\hline geométrico & 3 & 16,67 & 5 & 11,11 & 1 & 50,00 & 0 & 0,00 \\
\hline foliáceo & 8 & 44,44 & 30 & 66,67 & 1 & 50,00 & 14 & 100,00 \\
\hline aletas y pedúnculo & 5 & 27,78 & 9 & 20,00 & 0 & 0,00 & 0 & 0,00 \\
\hline aletas insinuadas & 2 & 11,11 & 1 & 2,22 & 0 & 0,00 & 0 & 0,00 \\
\hline pedunculadas & 0 & 0,00 & 0 & 0,00 & 0 & 0,00 & 0 & 0,00 \\
\hline GeOMÉtricos & 207 & 32,55 & 121 & 19,00 & 31 & 23,66 & 3 & 2,91 \\
\hline genérico $(\mathrm{F})$ & 7 & 3,38 & 5 & 4,13 & 4 & 12,90 & 1 & 33,33 \\
\hline trapecios & 87 & 42,03 & 81 & 66,94 & 18 & 58,06 & 2 & 66,67 \\
\hline triángulos & 30 & 14,49 & 12 & 9,92 & 0 & 0,00 & 0 & 0,00 \\
\hline rectángulos & 15 & 7,25 & 11 & 9,09 & 4 & 12,90 & 0 & 0,00 \\
\hline segmentos & 65 & 31,40 & 10 & 8,26 & 5 & 16,13 & 0 & 0,00 \\
\hline romboidales & 3 & 1,45 & 2 & 1,65 & 0 & 0,00 & 0 & 0,00 \\
\hline Perforadores & 58 & 9,12 & 70 & 10,99 & 15 & 11,45 & 8 & 7,77 \\
\hline taladro & 23 & 39,66 & 29 & 41,43 & 7 & 46,67 & 6 & 75,00 \\
\hline pico 'atípico' & 21 & 36,21 & 30 & 42,86 & 4 & 26,67 & 2 & 25,00 \\
\hline perforador con aleta & 4 & 6,90 & 0 & 0,00 & 0 & 0,00 & 0 & 0,00 \\
\hline perforador con pedúnculo & 3 & 5,17 & 1 & 1,43 & 0 & 0,00 & 0 & 0,00 \\
\hline punzón grueso & 2 & 3,45 & 0 & 0,00 & 0 & 0,00 & 0 & 0,00 \\
\hline perforador (genérico) & 3 & 5,17 & 6 & 8,57 & 4 & 26,67 & 0 & 0,00 \\
\hline perforador múltiple & 2 & 3,45 & 4 & 5,71 & 0 & 0,00 & 0 & 0,00 \\
\hline MicrobURILES & 3 & 0,47 & 4 & 0,63 & $\mathbf{0}$ & 0,00 & $\mathbf{0}$ & 0,00 \\
\hline RASPADORES & 54 & 8,49 & 46 & 7,22 & 5 & 3,82 & 3 & 2,91 \\
\hline laminar & 21 & 38,89 & 11 & 23,91 & 5 & 100,00 & 1 & 33,33 \\
\hline frente retocado & 20 & 95,24 & 11 & 100,00 & 5 & 100,00 & 1 & 100,00 \\
\hline frente no retocado & 1 & 4,76 & 0 & 0,00 & 0 & 0,00 & 0 & 0,00 \\
\hline lasca & 33 & 61,11 & 35 & 76,09 & 0 & 0,00 & 2 & 66,67 \\
\hline lasca delgada (grosor $<8 \mathrm{~mm})$ & 17 & 51,52 & 22 & 62,86 & 0 & 0,00 & 1 & 50,00 \\
\hline lasca gruesa (grossor $>8 \mathrm{~mm})$ & 16 & 48,48 & 13 & 37,14 & 0 & 0,00 & 1 & 50,00 \\
\hline RAEDERAS & 14 & 2,20 & 39 & 6,12 & 3 & 2,29 & 1 & 0,97 \\
\hline
\end{tabular}




\begin{tabular}{|c|c|c|c|c|c|c|c|c|}
\hline \multirow{2}{*}{ TeCnotipología } & \multicolumn{2}{|c|}{ VALL DEL LloP } & \multicolumn{2}{|c|}{ La Conca } & \multicolumn{2}{|c|}{ Vall de Mantons } & \multicolumn{2}{|c|}{ Vall de CarRinya } \\
\hline & $n$ & $\%$ & $n$ & $\%$ & $n$ & $\%$ & $n$ & $\%$ \\
\hline raedera retoque marginal & 1 & 7,14 & 4 & 10,26 & 0 & 0,00 & 0 & 0,00 \\
\hline raedera lateral & 10 & 71,43 & 16 & 41,03 & 3 & 100,00 & 1 & 100,00 \\
\hline raedera transversal & 0 & 0,00 & 2 & 5,13 & 0 & 0,00 & 0 & 0,00 \\
\hline raedera latero-transversal & 2 & 14,29 & 10 & 25,64 & 0 & 0,00 & 0 & 0,00 \\
\hline raedera carenoide & 0 & 0,00 & 7 & 17,95 & 0 & 0,00 & 0 & 0,00 \\
\hline raedera mixta & 1 & 7,14 & 0 & 0,00 & 0 & 0,00 & 0 & 0,00 \\
\hline LÁM. RETOQUE PLANO/SOBREELEVADO & 21 & 3,30 & 5 & 0,78 & 1 & 0,76 & 2 & 1,94 \\
\hline unilateral & 12 & 57,14 & 1 & 20,00 & 1 & 100,00 & 2 & 100,00 \\
\hline bilateral & 6 & 28,57 & 3 & 60,00 & 0 & 0,00 & 0 & 0,00 \\
\hline proximal & 3 & 14,29 & 1 & 20,00 & 0 & 0,00 & 0 & 0,00 \\
\hline distal & 0 & 0,00 & 0 & 0,00 & 0 & 0,00 & 0 & 0,00 \\
\hline Muescas/denticulados & 53 & 8,33 & 54 & 8,48 & 17 & 12,98 & 13 & 12,62 \\
\hline denticulados & 44 & 83,02 & 37 & 68,52 & 11 & 64,71 & 11 & 84,62 \\
\hline laminar unilateral & 17 & 38,64 & 15 & 40,54 & 9 & 81,82 & 5 & 45,45 \\
\hline laminar bilateral & 27 & 61,36 & 22 & 59,46 & 1 & 9,09 & 6 & 54,55 \\
\hline lasca delgada (grossor $<8 \mathrm{~mm}$ ) & 0 & 0,00 & 0 & 0,00 & 1 & 9,09 & 0 & 0,00 \\
\hline lasca gruesa $($ grosor $>8 \mathrm{~mm})$ & 0 & 0,00 & 0 & 0,00 & 0 & 0,00 & 0 & 0,00 \\
\hline muescas & 9 & 16,98 & 17 & 31,48 & 6 & 35,29 & 2 & 15,38 \\
\hline m. simple & 6 & 66,67 & 12 & 70,59 & 3 & 50,00 & 2 & 100,00 \\
\hline m. ret. & 1 & 11,11 & 4 & 23,53 & 3 & 50,00 & 0 & 0,00 \\
\hline $\mathrm{ms} / \mathrm{mr}$ & 2 & 22,22 & 1 & 5,88 & 0 & 0,00 & 0 & 0,00 \\
\hline Buriles & 17 & 2,67 & 15 & 2,35 & 9 & 6,87 & 3 & 2,91 \\
\hline buril de eje & 8 & 47,06 & 2 & 13,33 & 0 & 0,00 & 1 & 33,33 \\
\hline buril de ángulo & 0 & 0,00 & 1 & 6,67 & 2 & 22,22 & 0 & 0,00 \\
\hline buril transversal & 0 & 0,00 & 1 & 6,67 & 0 & 0,00 & 0 & 0,00 \\
\hline golpe de buril (genérico) & 9 & 52,94 & 11 & 73,33 & 7 & 77,78 & 2 & 66,67 \\
\hline buril múltiple & 0 & 0,00 & 0 & 0,00 & 0 & 0,00 & 0 & 0,00 \\
\hline LÁMINAS DE BASE ESTRECHA & 14 & 2,20 & 12 & 1,88 & 1 & 0,76 & $\mathbf{0}$ & 0,00 \\
\hline abatimiento parcial oblicuo & 7 & 50,00 & 6 & 50,00 & 1 & 100,00 & 0 & 0,00 \\
\hline simple & 5 & 71,43 & 5 & 83,33 & 0 & 0,00 & 0 & 0,00 \\
\hline doble & 2 & 28,57 & 1 & 16,67 & 1 & 100,00 & 0 & 0,00 \\
\hline escotadura & 7 & 50,00 & 6 & 50,00 & 0 & 0,00 & 0 & 0,00 \\
\hline simple & 5 & 71,43 & 5 & 83,33 & 0 & 0,00 & 0 & 0,00 \\
\hline doble & 2 & 28,57 & 1 & 16,67 & 0 & 0,00 & 0 & 0,00 \\
\hline Truncaturas & 59 & 9,28 & 50 & 7,85 & 12 & 9,16 & 10 & 9,71 \\
\hline LÁMINAS DE DORSO & 25 & 3,93 & 31 & 4,87 & 6 & 4,58 & $\mathbf{0}$ & 0,00 \\
\hline dorso arqueado & 13 & 52,00 & 17 & 54,84 & 3 & 50,00 & 0 & 0,00 \\
\hline dorso rectilíneo & 11 & 44,00 & 13 & 41,94 & 3 & 50,00 & 0 & 0,00 \\
\hline drs. arq./rect. (bilateral) & 1 & 4,00 & 1 & 3,23 & 0 & 0,00 & 0 & 0,00 \\
\hline LÁMINAS DE RETOQUE MARGINAL & 8 & 1,26 & 5 & 0,78 & 11 & 8,40 & 2 & 1,94 \\
\hline LASCAS RETOCADAS & 4 & 0,63 & 3 & 0,47 & $\mathbf{0}$ & 0,00 & 9 & 8,74 \\
\hline HOJAS CON FILO EMBOTADO & 21 & 3,30 & 30 & 4,71 & 7 & 5,34 & 4 & 3,88 \\
\hline NÚCLEOS (Y FRAGMENTOS DE NÚCLEO) & 17 & 2,67 & 37 & 5,81 & 3 & 2,29 & 12 & 11,65 \\
\hline TOTAL & 636 & 100 & 637 & 100 & 131 & 100 & 13 & 100 \\
\hline
\end{tabular}

FIG. 6. Tabla de recuento y porcentajes morfo-tecno-tipológicos de las cuatro áreas estudiadas. 

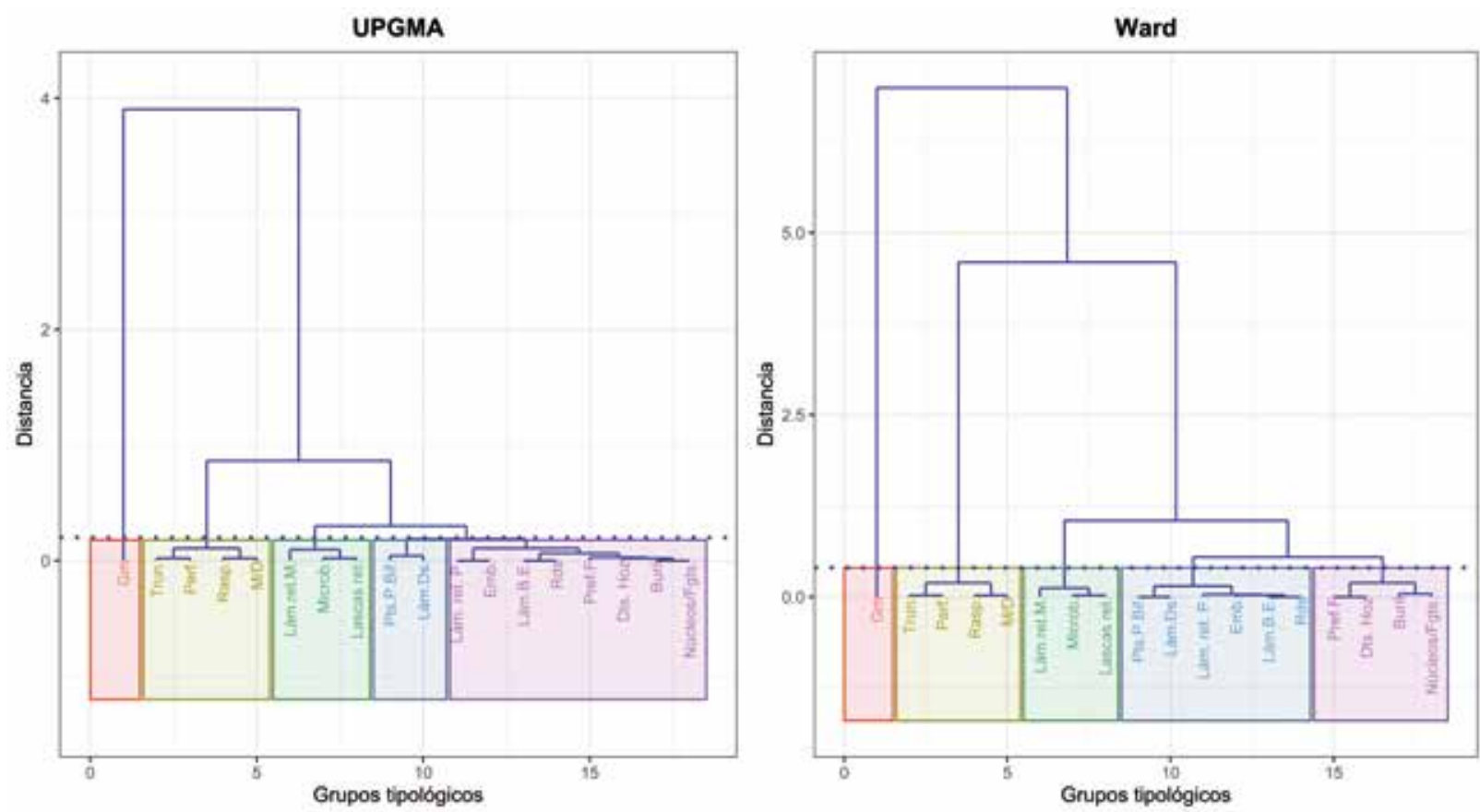

FIG. 7. Clúster de distancia euclídea con método UPGMA y Ward de los valores cuantitativos por cada tipología de las 4 muestras analizadas.

\begin{tabular}{|c|c|c|c|c|c|c|c|c|}
\hline \multirow{2}{*}{ SOPORTE } & \multicolumn{2}{|c|}{$\begin{array}{l}\text { VALL DEL } \\
\text { LLOP }\end{array}$} & \multicolumn{2}{|c|}{ LA Conca } & \multicolumn{2}{|c|}{$\begin{array}{l}\text { VALL DE } \\
\text { MANTONS }\end{array}$} & \multicolumn{2}{|c|}{$\begin{array}{l}\text { VALL DE } \\
\text { CARRINYA }\end{array}$} \\
\hline & $\mathrm{n}$ & $\%$ & $\mathrm{n}$ & $\%$ & $\mathrm{n}$ & $\%$ & $\mathrm{n}$ & $\%$ \\
\hline Lasca & 120 & 18,87 & 191 & 29,98 & 14 & 10,69 & 56 & 54,37 \\
\hline Laminar & 501 & 78,77 & 405 & 63,58 & 114 & 87,02 & 34 & 33,01 \\
\hline lámina & 449 & 89,62 & 380 & 93,83 & 107 & 93,86 & 31 & 91,18 \\
\hline laminita & 52 & 10,38 & 25 & 6,17 & 7 & 6,14 & 3 & 8,82 \\
\hline Núcleo & 15 & 2,36 & 33 & 5,18 & 3 & 2,29 & 10 & 9,71 \\
\hline Placa & 0 & 0 & 6 & 0,94 & 0 & 0 & 3 & 2,91 \\
\hline Nódulo & 0 & 0 & 2 & 0,31 & 0 & 0 & 0 & 0 \\
\hline TOTAL & 636 & 100 & 637 & 100 & 131 & 100 & 103 & 100 \\
\hline
\end{tabular}

FIG. 8. Tabla de clasificación productiva de los soportes de las cuatro áreas estudiadas.

proporcionalmente menores de núcleos unipolares de laminillas (Fig. 10, n. $\left.{ }^{\text {os }} 1-2\right)$, alguno de producción mixta, y otro de morfología bipiramidal. En menor presencia se configuran elementos discoides (Fig. 9, n. ${ }^{\circ}$ ), poliédricos (Fig. 9, n.o 4) o piramidales para la producción de lascado, teniendo en cuenta que

que evidencian un palimpsesto con un largo recorrido temporal y funcional. Los aspectos productivos que se presentan en la realización de los soportes laminares no se vinculan cuantitativamente, pero sí presencialmente, en la explotación y configuración de los núcleos identificados (Fig. 8).

Los núcleos mantienen cierta diversificación de configuraciones y morfologías, predominando la presencia de façonnage de lascado en centrípetos y uno de tipo tortuga. Se contrastan con productos se observan lascados destinados a reconfiguraciones de núcleos laminares (Fig. 9, n. ${ }^{\circ} 3$ ).

La producción laminar se vincula en amplio grado a distintos tipos de útil, principalmente destinada a la configuración de geométricos. Estos se relacionan con la técnica del microburil, constituyendo cierto nivel de variabilidad morfológica y de retoque en la bitruncadura del soporte. Paralelamente, este mismo soporte se reserva a útiles de sustrato, desde dorsos con diferentes delineaciones del abatimiento 
configurado, láminas fracturadas a modo de buril, elementos denticulados o truncaduras. Algunas de estas últimas adquieren intencionalidad técnica en la adaptación del enmangue -como aquellos útiles de corte longitudinal o bien transversal-, algunos a modo de raspador.

La producción secundaria de lascado, presente en los útiles retocados, principalmente tiende a un salto cronológico aparente definido por las puntas de proyectil bifaciales (Fig. 9, n. ${ }^{\text {s }} 8-10$ ), algunas con aletas y pedúnculo, con un notable grado de fragmentación -ya sea por su posible uso como por fracturación mecánica de labrado-. Con relación a las armaduras se constata el proceso de producción en varios esbozos o preformas foliáceas, elementos inacabados (Fig. 9, n. ${ }^{\circ}$ 11) con distintos niveles de reducción.

La heterogeneidad productiva se traslada a los elementos de hoz debido a la diferencia de complejidad técnica que adoptan. En este caso, destacamos la presencia de dientes de hoz que resultan significativos a partir del Calcolítico y Bronce Inicial, contraponiéndose con los elementos laminares denticulados de menor significación cronológica. En los primeros mencionados, la presencia de lustre en su hoja activa los caracteriza a la par con las denticulaciones regulares a distintos niveles de profundidad, presentando abatimientos abruptos ya sea por truncaduras o dorsos contrarios a la denticulación (Fig. 9, n. ${ }^{\text {os }}$ 12-14). Otros elementos de hoz con menor sensibilidad temporal aparecen sobre denticulaciones irregulares, o bien hojas con presencia de lustre y retoque no sistemático.

El resto de los útiles de sustrato pertenecientes a configuraciones del primer estadio tipológico se diversifican entre subtipos. En relación con los perforadores, destacan los taladros de configuración mèche -más característicos a partir del Neolítico- ${ }^{6}$. La menor presencia de configuraciones más microlaminares como picos 'atípicos' o punzones gruesos

6 Palomo, A.: Tecnologia lítica i de la fusta de la Prehistòria recent al nord-est peninsular. Anàlisi tecnomorfològica $i$ experimental. Tesis doctoral inédita presentada en 2012 en la Univ. Autònoma de Barcelona. sobre lasca evidencian cierta multiplicidad funcional y técnica de estos útiles.

\subsubsection{La Conca}

Con una producción y diversidad similar al conjunto anterior, la alta explotación y configuración de los núcleos se asocia a la diversificación de soportes (Fig. 8), presentándose façonnage de lascado preferentemente, pero complementándose con configuraciones laminares -más algunas pocas de laminillas (Fig. 10, n. ${ }^{\text {s }} 5$ y 6)-. Morfológicamente destacan los de tipo tortuga (Fig. 10, n. ${ }^{\circ}$ ), seguidos por las configuraciones poliédricas (Fig. 10, n. ${ }^{\circ}$ 4) y piramidales (Fig. 10, n. ${ }^{\circ}$ 6). Estas últimas con presencia exclusiva de producción laminar -algunas mixeadas a causa de reconfiguración nuclear-. Residualmente se presentan núcleos discoides (Fig. 10, n. $^{\text {os }} 2-3$ ), prismáticos, bipiramidales, écaillé y un núcleo reaprovechado como percutor.

El predominio del componente laminar como soportes sobre los retocados se relaciona intrínsecamente con las producciones geométricas -combinado en menor proporción con las laminillas- más su realización mediante la técnica del microburil. Presentan generalmente gran diversidad morfológica -triángulos, trapecios, segmentos, rectángulos- junto con cierta variabilidad de retoque en la bitruncadura, destacando el doble bisel.

Otros elementos secundarios vinculados a estos soportes se presentan exclusivamente en elementos de dorso, truncaduras y la producción de elementos de hoz, ya sea sobre muescas y denticulados como también aquellos específicamente más tardíos -dientes de hoz (Fig. 10, n. ${ }^{\text {ss }} 10-12$ )-. A estos se les suman, con menor peso, producciones buriloides de distintos subtipos.

Para el lascado cabe destacar, en segundo lugar, su relación con las puntas de proyectil bifaciales (Fig. 10, n. ${ }^{\text {os }} 7-9$ ), complementándose con preformas bifaciales de distintos niveles de reducción. Otras producciones dentro de los útiles de sustrato con soportes de lasca se encuentran configuradas a modo de raederas, raspadores y perforadores, con un alto grado de diversidad morfotécnica. Estos 

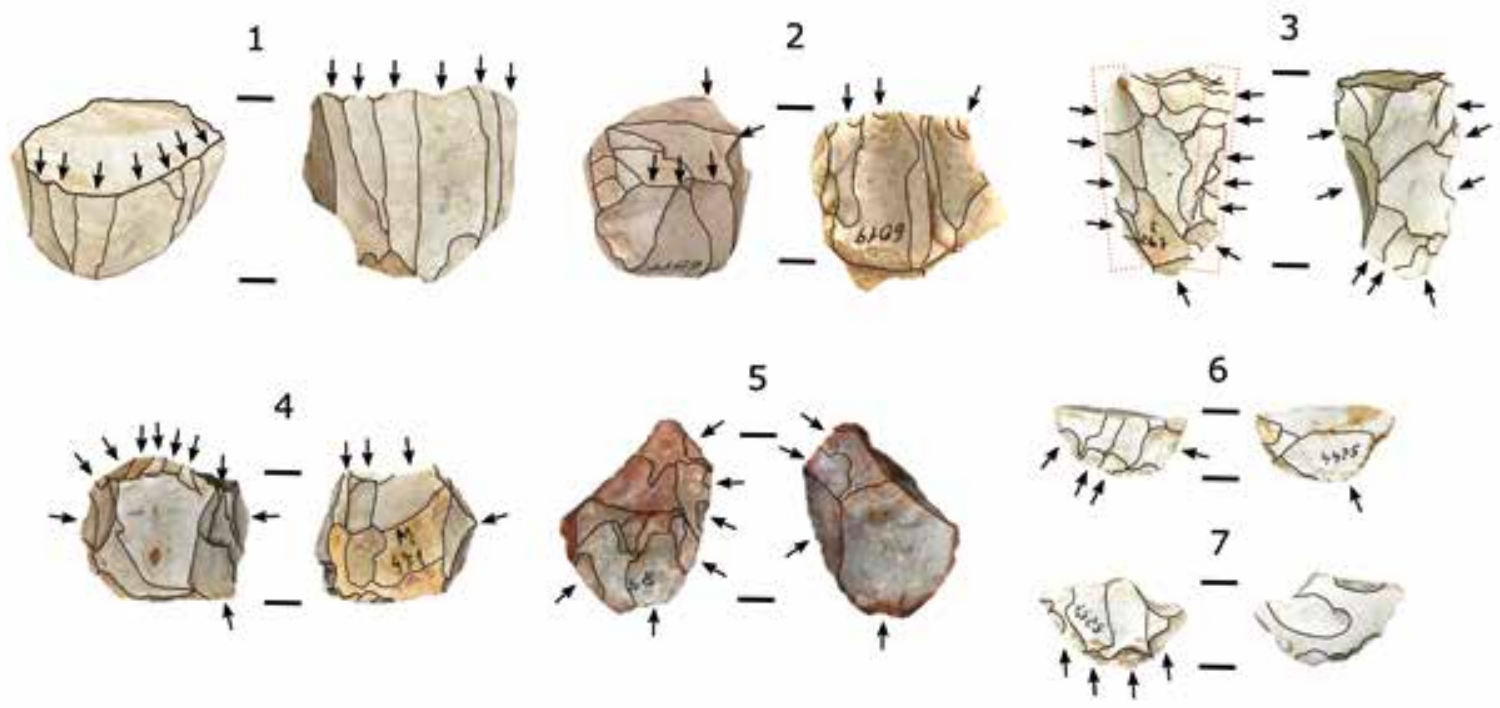

8

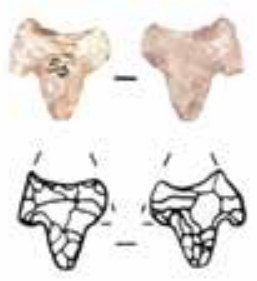

12
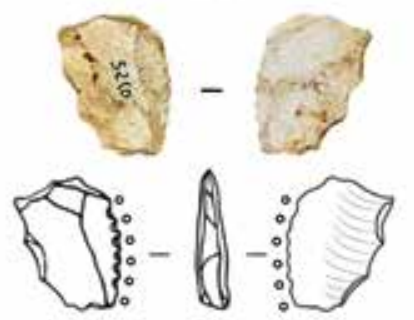

।

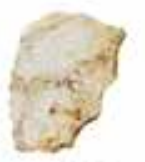

:
9
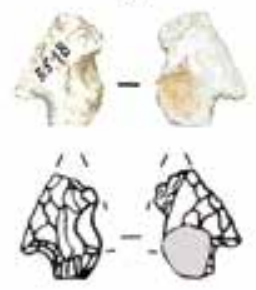

13

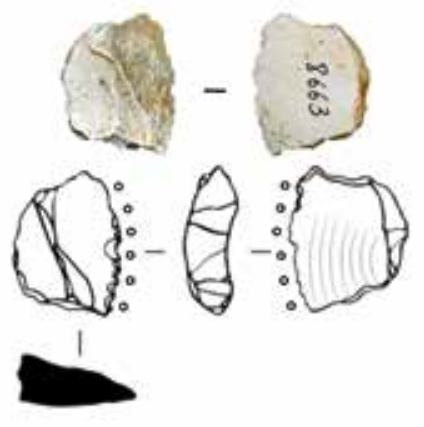

10
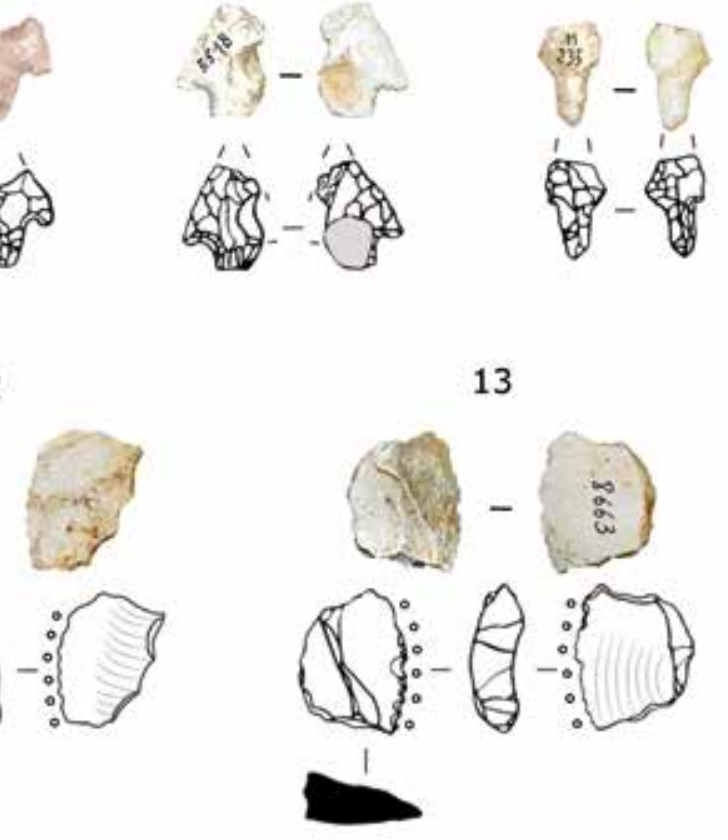

11

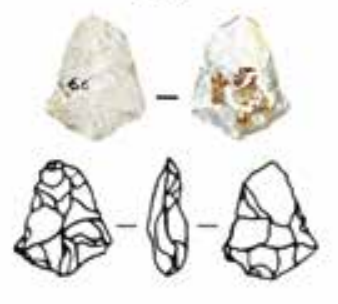

14

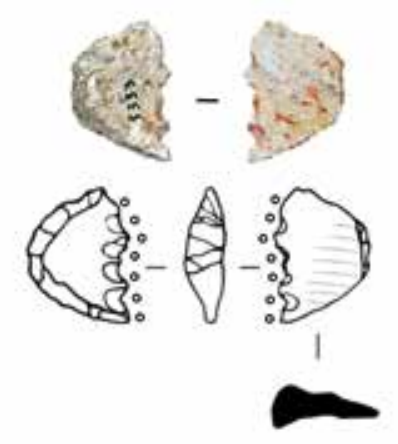

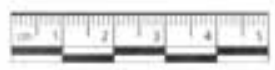

Fig. 9. Muestra de elementos líticos del conjunto de la Vall del Llop: 1-2) núcleos unipolares laminares -laminillas- con reconfiguración de la plataforma de talla; 3) núcleo piramidal de lascado como reconfiguración de núcleo laminar - realización de doble cresta irregularizada-; 4) núcleo poliédrico de extracción mixta; 5) fragmento de núcleo discoide de lascado con dirección centripeta; 6-7) fragmentos de núcleo tortuga de variedad laminar; 8-10) puntas con aletas y pedúnculo bifaciales; 11) preforma romboidal bifacial; 12-14) dientes de hoz con lustre. 
1

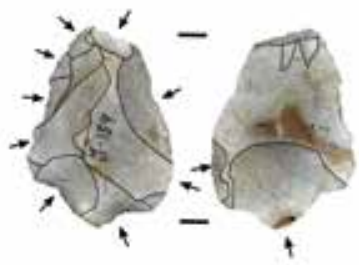

4

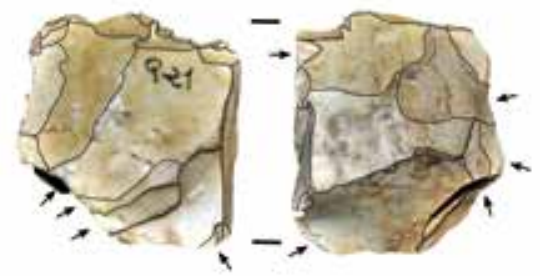

7
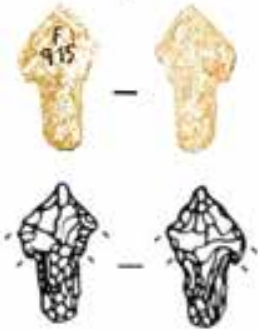

10

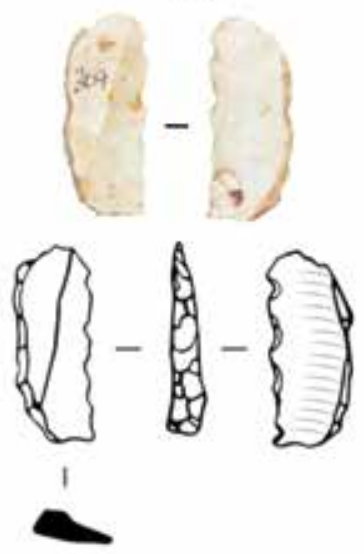

2

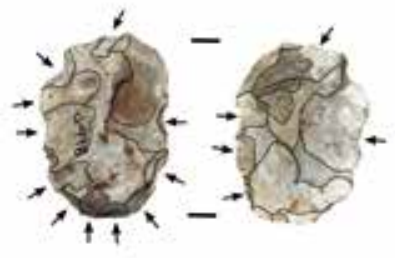

5

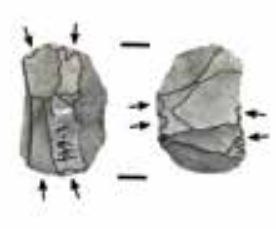

8
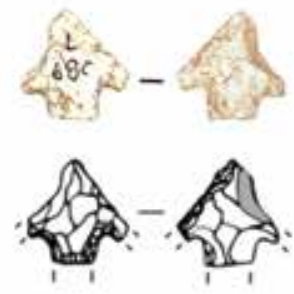

11
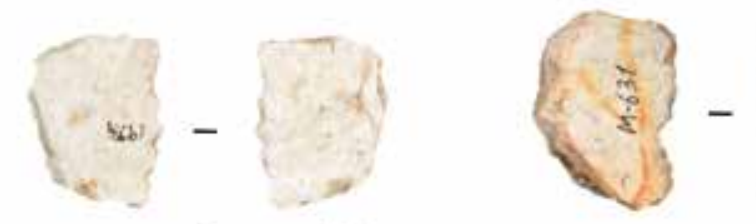

12
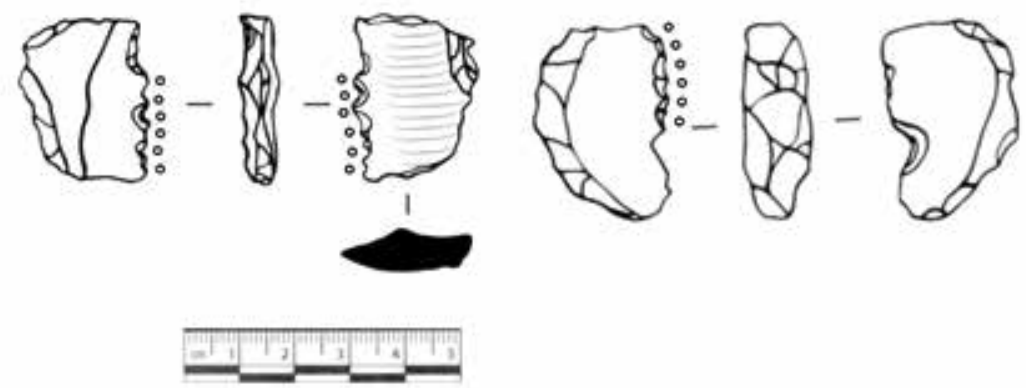

Fig. 10. Muestra de elementos líticos del conjunto de La Conca: 1) núcleo tipo tortuga-variedad lasca-; 2-3) núcleos discoides de lascado centripetos; 4) núcleo poliédrico; 5) núcleo bipolar laminar-laminillas-; 6) fragmento de núcleo unipolar laminar-laminillas-; 7-9) puntas con aletas y pedúnculo bifaciales; 10-12) dientes de hoz. 
últimos son equitativos para ambas producciones de soportes combinando tanto taladros como microperforadores. Principalmente a estos últimos se asocian picos atípicos y escasos perforadores de punta múltiple -o de tipo 'estrella' (Merino, 1994)-. En este sentido, una tercera producción se adhiere al conjunto realizado sobre placas tabulares. Aunque su presencia es escasa, se refleja en una raedera y un posible elemento de hoz, reforzando cronologías tardías de la Prehistoria Reciente (Neolítico Final-Calcolítico).

\subsubsection{Vall de Mantons}

Las evidencias del predominio de soporte no se reflejan en las configuraciones de los núcleos recuperados, siendo cuantitativamente escasos y con poca representatividad (Fig. 8). Un solo núcleo poliédrico constituye la evidencia de producción laminar-aunque mixeada con el lascado (Fig. 11, n. ${ }^{\circ}$ 2)-, más dos núcleos restantes -bipiramidal (Fig. 11, n.o 3)- solamente de lascado. El último presenta indicios de percusión y extracciones de lascas fruto de estos, pudiendo pertenecer a un útil macrolítico sobre sílex (Fig. 11, n. ${ }^{\circ}$ 1). La estandarización productiva se manifiesta sobre el componente laminar - y menor proporción de laminillas- junto con un segundo plano de lascados. La extracción de lascas se destina limitadamente a la configuración de puntas bifaciales y preformas (Fig. 11, n. ${ }^{\text {s }} 4-5$ ). También aparecen paralelamente algunos útiles de fondo - perforadores, raederas y muescas/denticulados-. Las producciones laminares vuelven a predominar con relación a la confección de geométricos.
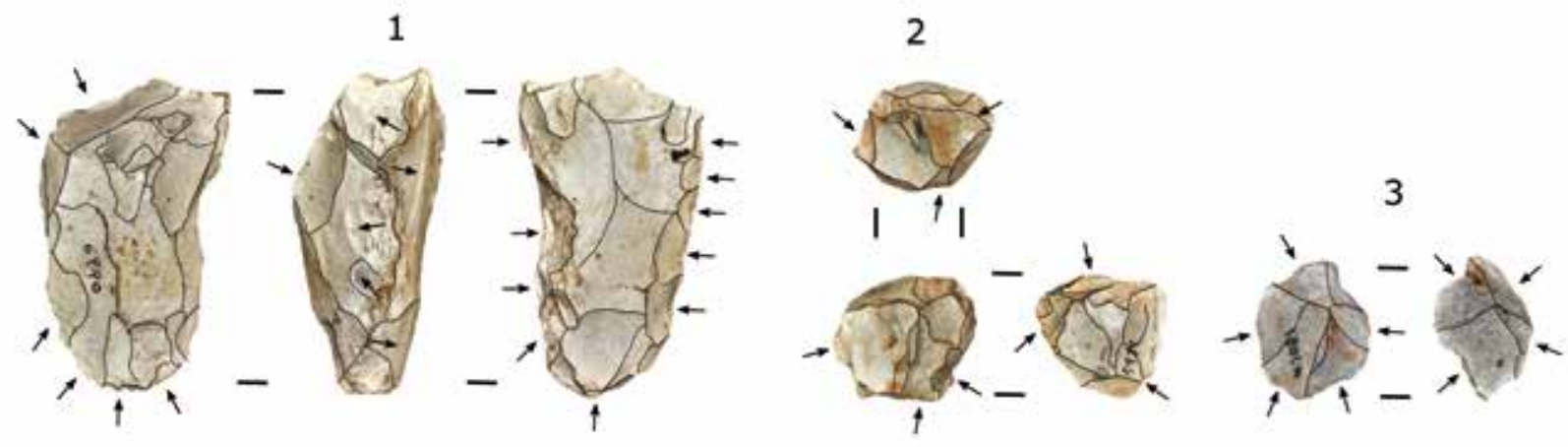

4

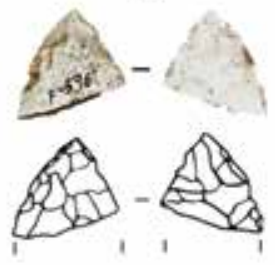

5

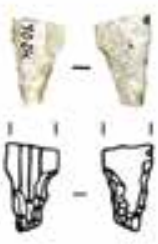

6

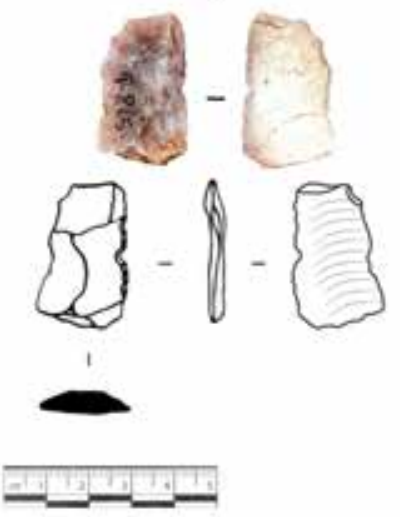

7

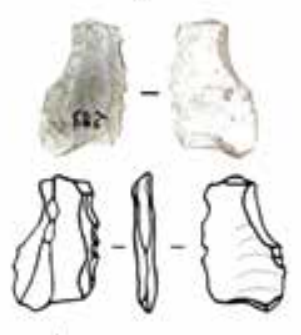

,

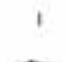

Fig. 11. Muestra de elementos líticos del conjunto de la Vall de Mantons: 1) núcleo de lascado con indicios de percusión; 2) núcleo poliédrico; 3) núcleo bipiramidal; 4-5) puntas fragmentadas; 6-7) dientes de hoz. 
Cuantitativamente destacan los trapecios y, en menor medida, los segmentos, su totalidad en doble bisel. Por contra, no se constatan evidencias del empleo del microburil en relación con los procedimientos técnicos vinculados con el geometrismo. Otros útiles sobre soporte laminar se reservan para la mayoría de los elementos de sustrato -láminas de dorso, truncaduras, láminas de retoque plano, láminas de base estrecha y muescas/denticulados, este último con un solo efectivo de lascado- más algunos con mayor especificación cronológica, tales como los dientes de hoz -aunque escasos, Fig. 11, n. ${ }^{\text {os }} 6-7-$ y perforadores, dentro de estos de tipo mèche frente a la poca diversificación morfo-tecnotipológica -picos y taladros-.

\subsubsection{Vall de Carrinya}

Las configuraciones productivas vinculadas a este conjunto difieren del resto en cuanto a los soportes principales (Fig. 8). En primer lugar, el predominio de lascado deja en segundo plano el laminar. Este último se limita a la casi ausencia de las producciones geométricas y su enfoque hacia los útiles de sustrato -truncaduras, muescas y denticulados, buriles y perforadores-. Aun así, se debe tener en cuenta la relación entre los pocos soportes laminares presentes con la configuración de núcleos de façonnage laminar. Dentro de los núcleos analizados, se combinan las extracciones laminares y de lascado -de morfología mayoritariamente piramidal-, sin tener ningún núcleo exclusivamente laminar. El resto de los elementos nucleares corresponden al lascado con morfologías poliédricas predominantes, más uno bipiramidal, todos con alto grado de explotación hasta su amortización (Fig. 12, n. ${ }^{\text {os }} 1-3$ ).

A la presencia marginal de geométricos en este nivel -tan solo con la recuperación de tres elementos, solamente dos identificados como trapecios- se le añade contrariamente un aumento significativo

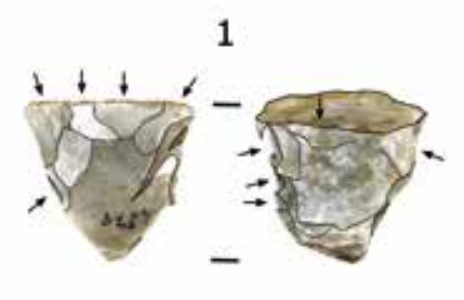

2

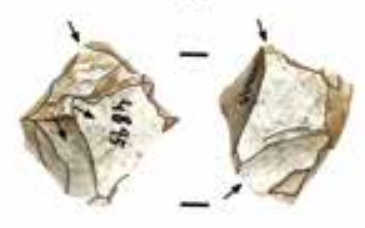

3

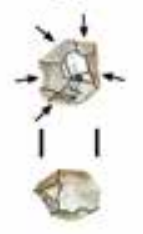

4

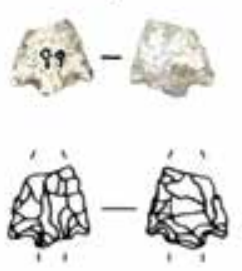

5

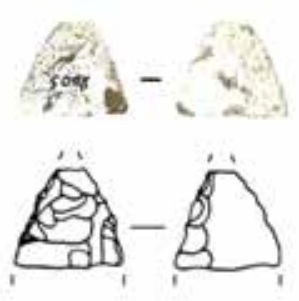

6

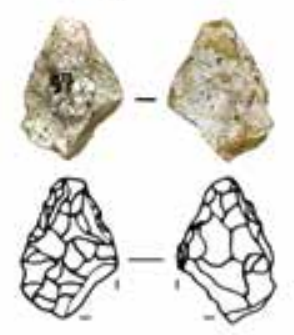

7

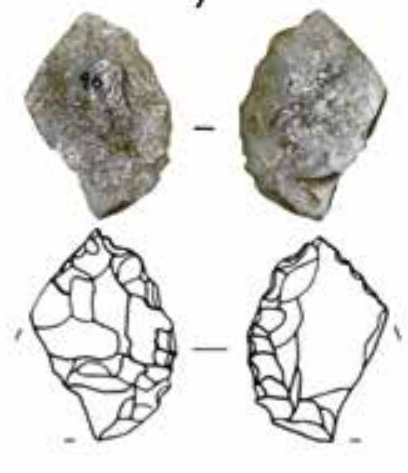

8
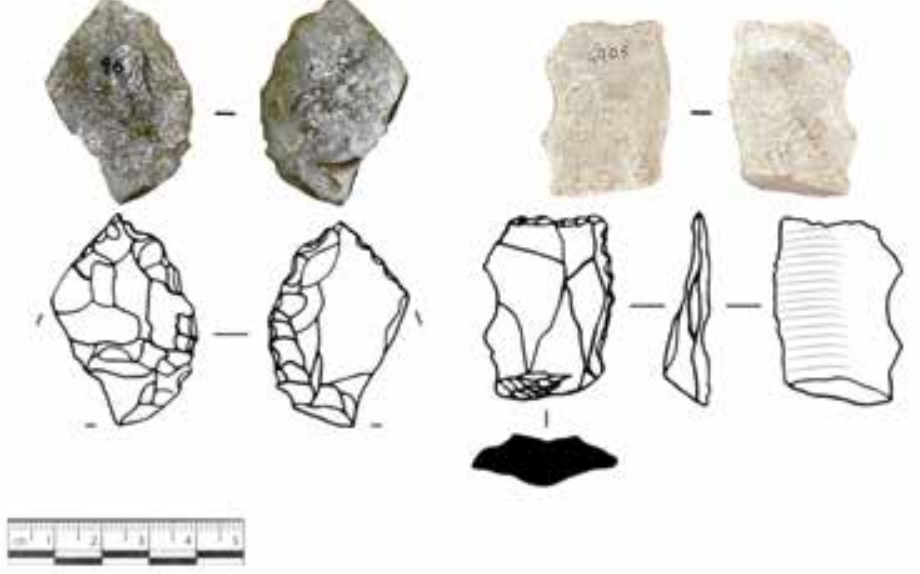

Fig. 12. Muestra de elementos liticos del conjunto de la Vall de Carrinya: 1) núcleo unipolar piramidal de lascado (posible reconfiguración laminar); 2) núcleo bipiramidal de lascado; 3) núcleo discoide. 4-7) puntas bifaciales; 8) diente de hoz. 
de los elementos bifaciales -tanto puntas como esbozos (Fig. 12, n. ${ }^{\text {os }}$ 4-7)-. La importancia de los elementos de cronologías más tardías supone una menor duración de la deposición del palimpsesto, si exponemos la presencia de preformas bifaciales, los dientes de hoz (Fig. 12, n. ${ }^{\circ}$ ) y los útiles sobre placa, reduciendo la horquilla cronológica del conjunto.

El resto de los elementos presentes se enfocan hacia el predominio de las configuraciones y aprovechamiento de los soportes de lascado. Principalmente en referencia a los útiles de fondo, desde tipos primarios como perforadores, raspadores y raederas -esta última sobre placa-, como también sobre muescas y denticulados sin ser predominantes. La industria laminar, por ende, se reserva a los útiles secundarios y terciarios, desde componentes de dorso, truncaduras y escasos buriles, hasta láminas de retoque marginal y de filo embotado.

\section{Aproximación cronológica}

A partir de los resultados categóricos obtenidos, las producciones documentadas, principalmente geométricos y puntas de proyectil, son de gran utilidad para la obtención de una cronología más robusta. En estos casos la distribución de las clases adscritas al modelo comprende un total de 297 elementos distribuidos en los 4 conjuntos (Fig. 13).
Con la exposición de las clases identificadas en el conjunto cabe añadir algunos de los artefactos y características no utilizadas en la modelización bayesiana (Gironès et al., 2020) que puedan inferir en la definición y reforzar los períodos que se representan a través del análisis de geométricos y puntas de proyectil.

De acuerdo con la computación de las clases resultantes, los datos obtenidos tienden a varias adscripciones cronológicas (Fig. 14). En un primer momento, la tendencia máxima de los picos probabilísticos se sitúa en cronologías asociadas al Neolítico Final y el Calcolítico en La Conca y en la Vall de Carrinya. Por el contrario, los más antiguos se ubican entre el Epipaleolítico y el Sauveterriense en la Vall de Mantons y la Vall del Llop. Existe, por 


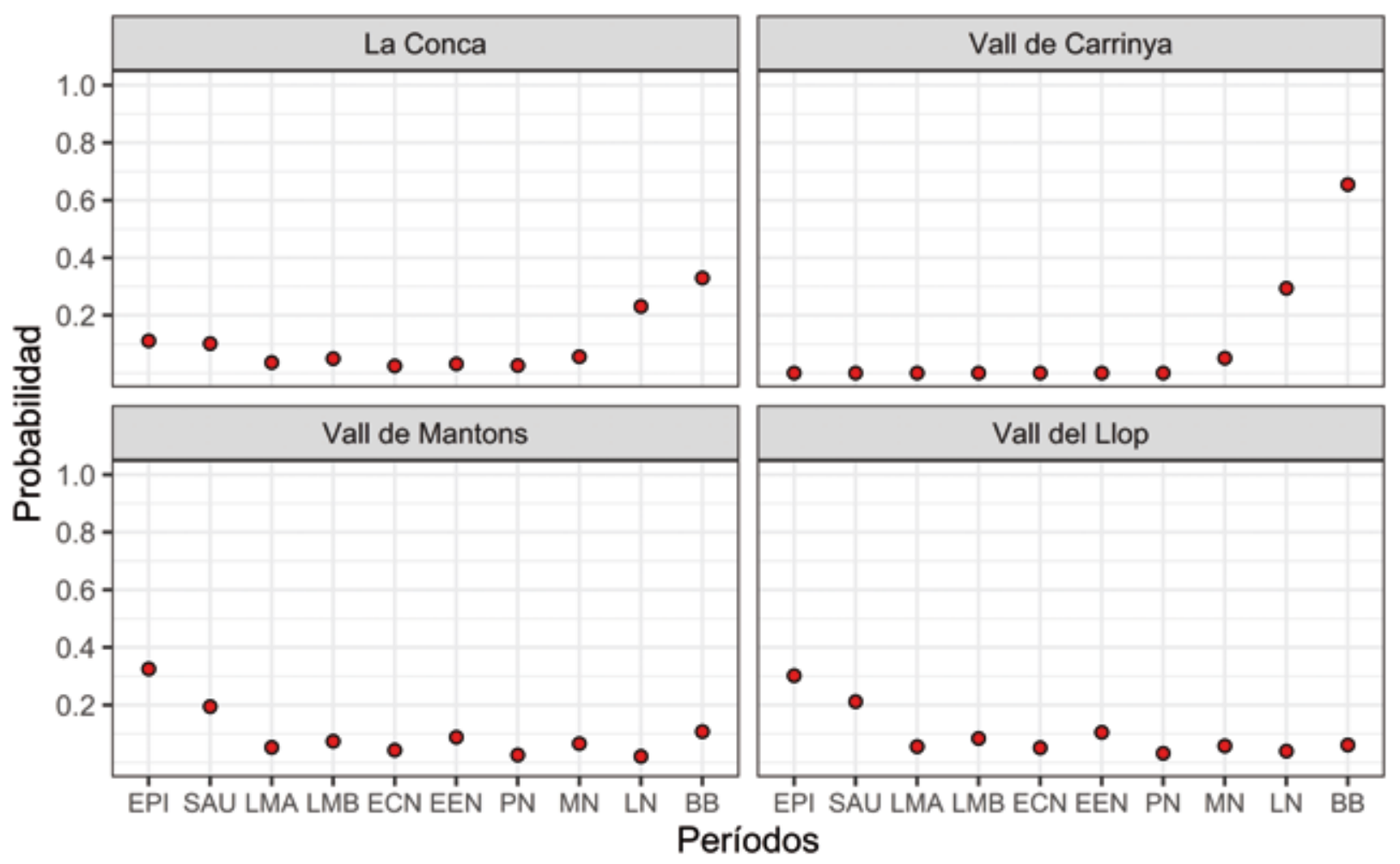

FIG. 14. Gráficos de probabilidad cronológica de los conjuntos liticos estudiados (0-1): EPI = Epipaleolítico; $S A U=$ Sauveterriense; $L M A=$ Mesolitico Final $A ; L M B=$ Mesolítico Final $B ; E C N=$ Neolitico Antiguo Cardial; EEN = Neolítico Antiguo Epicardial; $P N=$ Neolitico Poscardial; $M N=$ Neolitico Medio; $L N=$ Neolitico Final; $B B=$ Campaniforme.

ende, la multiplicidad cronológica en cada uno de ellos, identificándose diversos estadios productivos dentro del palimpsesto.

Se ha constatado un escaso registro de puntas de dorso laminares en las tres áreas -La Conca, Vall del Llop, Vall de Mantons- pero estas están ausentes en la Vall de Carrinya. La presencia de dichas puntas se combina junto con otras producciones relacionadas con la industria sauveterriense de tipo Filador, enfatizando en este caso la aparición de dorsos junto con triángulos escalenos con retoque abrupto -La Conca y la Vall del Llop-. Esta industria se ha identificado en algunos conjuntos asociados al Mesolítico del Bajo Aragón -Botiquería 2 y 4, Forcas II (II-IV), Secans IIb- y en el área valenciana -Cocina I-II-.

La mayor cuantificación de geométricos de tipo segmento se localiza en la Vall del Llop, predominantemente a doble bisel frente al retoque abrupto. Conduce su asociación probabilística hacia eventos del Neolítico Antiguo y Medio, también presentes en la Vall de Mantons -principalmente destacando los segmentos a doble bisel-. En La Conca, por el contrario, aparecen con escasas proporciones. Las producciones en segmento se expanden a partir del Mesolítico Geométrico Fase в, caracterizados por el retoque abrupto, tanto en yacimientos del Bajo Aragón -Forcas II, Nivel IV- (Utrilla et al., 2014) como en el Mediterráneo peninsular -Cocina II, Mas Cremat IV-v (Fortea, 1973; Gabarda et al., 2010). Su tendencia se reduce posteriormente por la emergencia del doble bisel, circunscribiendo su cambio de configuración a partir del Neolítico Antiguo Cardial -7600-7200 cal BP- (Alday, 2018). El importante predominio de trapecios en base a diversos morfotipos parte del Mesolítico Reciente, Fase A. Estos se documentan en Botiquería 2, Costalena c3 y Pontet $e$ (Alday et al., 2012: 323); Forcas II (Utrilla et al., 2014); Cocina I (Fortea, 1973; Martí et al., 2009), 
y Benàmer I (Gabarda et al., 2010; Jover, 2011) en contexto valenciano; se expanden hasta el Neolítico Medio en el Ne peninsular, como en Timba d'en Barenys (Miró, 1994), Mas Duran ${ }^{7}$ o Camí Can Grau (Martí et al., 1997). En contexto centromediterráneo la horquilla cronológica de esta clase se amplía hasta el Neolítico Final, principalmente visibles en Ereta del Pedregal (Juan-Cabanilles, 2008), Tábegues (Fernández-López de Pablo, 2006) y Niuet (García-Puchol, 2005). Observamos su clara presencia en nuestro caso de estudio en las tres áreas, destacando La Conca, con mayor representación de trapecios frente a segmentos, y en la Vall del Llop, siendo inversamente representados con el predominio de segmentos frente a trapecios.

La diversidad geométrica sigue presentándose en menores proporciones con los triángulos, reflejados en La Conca y la Vall del Llop, normalmente asociados a niveles comprendidos desde el Sauveterriense -Filador 5-6 y 7-, Mesolítico Geométrico, fase B, en contextos aragoneses -Botiquería 2, Forcas II (II-IV), Secans IIb-, y centromediterráneos -Cocina I-II, Mas Cremat VI-v y Benàmer I-. Regionalmente tenemos como referente el yacimiento de la Cova del Vidre ${ }^{8}$

7 Plasencia, F. J.: Bòbila Madurell-Mas Duran: Formas de vida en el Neolítico medio y final del nordeste peninsular. Tesis doctoral inédita presentada en 2016 en la Univ. Autònoma de Barcelona.

8 Bosch, J.: El procés de neolitització a la regió del curs inferior de l'Ebre. Tesis doctoral inédita presentada en 2005 en la Univ. de Barcelona.

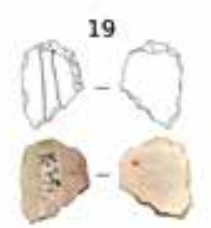

23

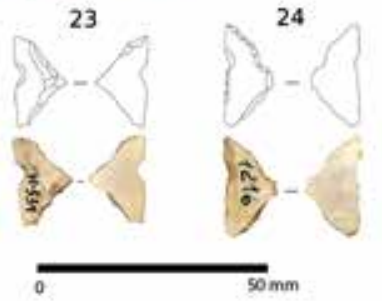

20

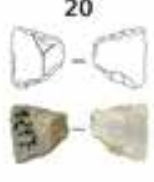

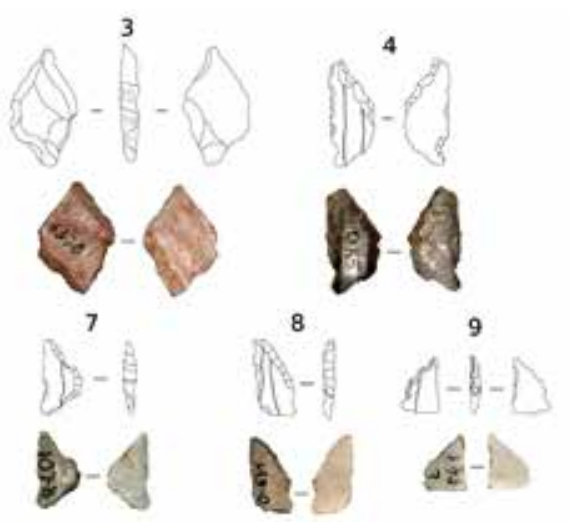

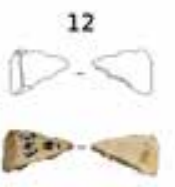

17

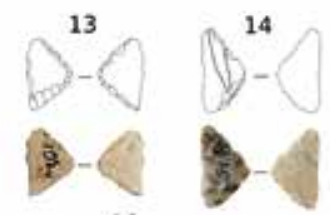

18
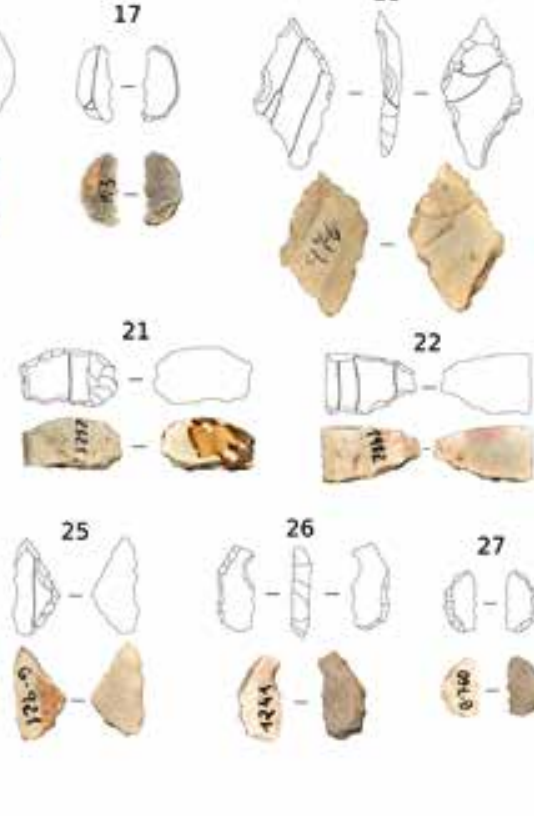

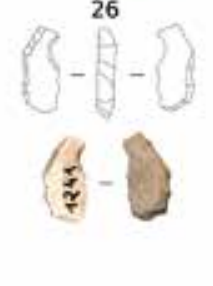

27

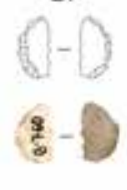

FIG. 15. Geométricos pertenecientes a las terrazas estudiadas: 1-2) Vall de Mantons; 3-17) Vall del Llop; 18-27) La Conca.

(Bosch, 2011) que a su vez comparte paralelismos con las producciones de Botiquería dels Moros (Barandiarán, 1978), Costalena (Barandiarán y Cava, 1989), el Abrigo de Pontet (Mazo y Montes, 1992) o el Abrigo de Secans (Rodanés et al., 1996). Cabe destacar la presencia de un triángulo de tipo Cocina el cual, junto con otros de los tipos vinculados a 
los conjuntos contextualizados anteriormente mencionados, podría aproximarse a la presencia de este tipo de producciones de momentos del Mesolítico Geométrico en La Conca, entre otros rangos cronológicos (Fig. 15).

\section{Discusión}

La gran variedad tipológica presente en los conjuntos define unas producciones heterogéneas de diversos útiles para su uso en diferentes actividades. Teniendo en cuenta la localización de cada una de las áreas, se presentan diversos focos acumulativos de los conjuntos que difieren claramente en su sentido cronocultural. Los elementos no incluidos en el modelo, como todos aquellos aspectos productivos presentes en el conjunto, pueden emplearse como complemento a la adscripción relativa bajo los preceptos de contextos regionales del NE Peninsular. En estos casos la variabilidad muestreada en varias de las áreas tiende a presentar una menor significación entre la Vall de Mantons y la Vall de Carrinya -afectando, a su vez, a la muestra de clases para el modelo-. Ambos conjuntos requieren de una mayor ampliación de la muestra con la inclusión de otros elementos no modelizados, los cuales podrían igualar en peso con las dos áreas restantes. Para ello, deben considerarse las producciones que puedan discernir sobre la adscripción cronológica. Así pues, a modo de observación cronocultural y productiva de los conjuntos, las configuraciones laminares - registradas en las cuatro áreas- destacan por la producción de geométricos -excepto la Vall de Carrinya-, predominantemente destinados a las morfologías trapezoidales y subtipos dentro de estas. Cuantitativamente cobran importancia los segmentos, sobre todo documentados en La Conca -combinando tanto de retoque abrupto como a doble bisel-. En un segundo término aparecen triángulos y rectángulos en dichas áreas. Junto con las configuraciones laminares de los núcleos definidos se vinculan ambos aspectos destinados a los geométricos, llegando a detectar fragmentos residuales identificados como restos de la técnica microburil, en La Conca y la Vall del Llop. Dichos elementos aparecen regionalmente sobre cronologías que parten del Epipaleolítico hasta el Neolítico Antiguo -7900-6800 cal вP-, asociados a la industria de Cova del Vidre ${ }^{9}$, Abric Filador (García-Argüelles, 2002; García-Argüelles et al., 2005) y en contextos aragoneses como Abrigo del Pontet (Barandiarán y Cava, 2000) y Riols I (Royo y Gómez, 1992; Gómez et al., 1992). Estas producciones se complementan con elementos de hojas truncadas, láminas de dorso y láminas de retoque plano o de base estrecha, conduciendo el eje de la producción hacia un alto grado de aprovechamiento y reconfiguración de los núcleos. Normalmente se vinculan a elementos de corte adaptados para el enmangue, sumándole la presencia más tardía de dientes de hoz con referentes próximos fechados en Minferri ( $\mathrm{Pa}-$ lomo et al., 2012).

En las últimas dos áreas mencionadas, las producciones de lascado dan forma a elementos de hoz denticulados. Como hemos visto, el lustre en la hoja activa caracteriza el trabajo de corte longitudinal producido tal y como estipulan algunos estudios traceológicos y experimentales ${ }^{10}$. A esto se le complementa la ausencia de denticulación a causa del desgaste en algún caso, aunque se configura el mismo abatimiento de dorso unido con truncadura o bitruncadura -configurando morfologías tanto rectangulares como triangulares, en menor medida-. Se realiza así la adaptación del enmangue, piezas clave para su uso en actividades agrícolas. Además, se encuentran producciones estandarizadas y en proporciones mínimas de raspadores, de morfotecnia diversificada, siendo los laminares los que presentan mayor desgaste del frente en su mayoría quedando un frente rectilíneo.

9 Bosch, op. cit. n. 8.

10 Gibaja, J. F.: La función de los instrumentos líticos como medio de aproximación socio-económica: comunidades neoliticas del V-IV milenio cal BC en el noreste de la Peninsula Ibérica. Tesis doctoral inédita presentada en 2002 en la Univ. Autònoma de Barcelona. También $c f$. Palomo, A.: Tecnologia lítica $i$ de la fusta de la Prehistoria recent al nordest peninsular. Anàlisi tecnomorfològica i experimental. Tesis doctoral inédita presentada en 2012 en la Univ. Autònoma de Barcelona. 
La presencia significativa de perforadores presenta diversas morfologías de taladros, algunos de tipo mèche y otros con presencia de pedúnculo, de cuerpo tanto circular como rectangular, según el morfotipo de la pieza. Su definición enfatiza cronologías a partir de 7600 cal вр у se han documentado en otros yacimientos como La Caserna de Sant Pau (Borrell, 2008), Guixeres de Vilobí (Mestres, 1987) o Timba d'en Barenys (Miró et al., 1992), así como en territorio centromediterráneo, como Cova de l'Or (Juan-Cabanilles, 2008). Todos comparten la configuración del apuntamiento mediante retoque abrupto bilateral, algunas de las áreas presentando tipos más específicos, tales como el punzón grueso -La Conca- o los perforadores de 'pico múltiple' o de tipo 'estrella' (Merino, 1994) -La Conca y la Vall del Llop-.

Otra de las producciones significativas se centra en la fabricación de puntas de proyectil, reflejada tanto en las mismas como en las preformas identificadas en todos los casos de estudio. Estas últimas, junto con la observación de diversos estadios de reducción de la materia tanto en las preformas como en los núcleos -como la aparición de útiles sobre elementos de reavivado-, estipulan la talla in situ en los espacios. La diversificación tipológica de puntas se centra en diferentes estadios productivos sobre todo dentro de la morfotécnica bifacial, dando lugar a tipificaciones que parten del Neolítico Final-Calcolítico y el Campaniforme, probablemente también en vínculo con cronologías del Bronce -5600-4200 cal вр-. En tal caso, cabe destacar la probabilidad de puntas bifaciales relacionadas con las primeras producciones de retoque bifacial, no cubriente. Tenemos ejemplos claros en contextos del Neolítico Medio Pleno como en el sepulcro de Garrofers del Torrent de Santa María (Martín y Miret, 1990) o en las Minas de Gavà (Borrell, 2009: 116). Aun así, las más representadas corresponden a varias morfologías bifaciales con heterogeneidad técnica de aletas y pedúnculos, mediante retoque plano bifacial, generalizadas a partir del Neolítico Final (Gibaja et al., 2010). Aparecen en contextos espacialmente cerrados, sea en el ajuar funerario calcolítico del

Ediciones Universidad de Salamanca / 요요 sepulcro de Costa de Can Martorell ${ }^{11}$, presentando gran variedad de morfotipos pedunculados, como en el contexto similar de Carrer París (Gibaja et al., 2006).

La diferencia principal que remarcamos, una vez más, la encontramos en la Vall de Carrinya. Siendo la menor en términos de diversificación tipológicay la que se compromete a un cambio de la industria enfocada a las proporciones, nos encontramos con el predominio del lascado y una escasa cantidad de geométricos. Se contrapone más la presencia predominante de producciones bifaciales destinadas a puntas, sumándose multitud de preformas. A esto, se une la ausencia total de elementos de dorso y microburiles, donde la producción laminar se centra en la configuración de truncaduras, láminas de retoque plano, buriles, láminas de retoque marginal y hojas con embotadura, con ínfimas proporciones. En este sentido, la exclusión de diversos elementos mencionados que no se encuentran adscritos en la modelización pueden ahondar en la rigurosidad del modelo si incluyesen ya sean aspectos tecnológicos como tipométricos que se encuentran presentes como marcadores cronológicos.

\section{Conclusiones}

Los conjuntos líticos superficiales analizados responden a diferentes momentos cronológicos dentro del microespacio considerado, como también a unas producciones enfocadas a distintos tipos de actividades. La variabilidad del conjunto, que se corresponde con una multiplicidad de eventos y de distintas acciones, expone una diversificación de niveles y de diferente duración. Si bien el análisis de dicho material marca ciertos paralelismos a escala regional tanto en la cuenca media del Ebro como en el arco mediterráneo peninsular, las producciones se caracterizarían de forma evidente si proviniesen de contextos cerrados o in situ. De este modo, la categorización del material y su asociación cronológica ayudan a la comprensión de las diferentes dinámicas

11 Gibaja, op. cit. n. 10; Palomo, op. cit. n. 10. 
ocupacionales a lo largo de la Prehistoria Reciente. Tenemos como prueba de ello varios ejemplos en otros trabajos donde se analizan y adscriben cronológicamente los conjuntos superficiales mediante técnicas multieventuales de probabilidad (Bernabeu et al., 1999; Barton et al., 2002; Pardo-Gordó et al., 2015; Snitker et al., 2018, entre otros).

La aproximación realizada en este trabajo nos permite discernir en torno a las ocupaciones reiterativas en un mismo lugar con variabilidad funcional del espacio. A su vez, proporciona marcar cierta continuidad en torno a las características físicas del paisaje para el control de los recursos, su fácil accesibilidad y su heterogeneidad concedida por el cauce fluvial y sus afluentes. A esto debe incorporarse la ausencia de investigaciones sistemáticas y el escaso peso de intervenciones arqueológicas que contemplen la Prehistoria Reciente en esta parte del cauce del Ebro, por lo que el presente estudio permite aproximarnos a sus espacios originarios en varios rangos cronológicos no lineales. La definición de los criterios temporales se vincula, ya sea por superposición o por establecimiento de actividades al aire libre a lo largo de las terrazas cuaternarias de la vía fluvial, a materiales dispersos en un largo recorrido sobre estas (Esteve-Gálvez, 2000). Estas concentraciones de material arqueológico proporcionan información sobre los diferentes tipos de producción. Ya sea relacionados tanto con las características regionales de los conjuntos y a los contextos de referencia más cercanos -actualmente disponibles- como en la información espacial que puede contemplar la presencia de ocupaciones. Su identificación y su aproximación cronocultural son un punto clave para poder definir posibles excavaciones arqueológicas, con el objetivo de completar mejor la información sobre las últimas sociedades cazadoras-recolectoras y las primeras comunidades campesinas en el sur del NE peninsular.

Sin embargo, la correspondencia de estos análisis sobre materiales descontextualizados no se presenta como asociaciones cronológicas absolutas. Partimos de algunos puntos en que el análisis pierde definición en torno a posibles cronologías con materiales líticos de fondo -periodizaciones

Ediciones Universidad de Salamanca / 요요 vinculadas a muescas y denticulados-, lo cual define un vacío de registro. Este vacío caracterizaría cierta ruptura tecnológica con el cambio de las producciones, sin poder dar con marcadores cronológicos fiables (Vaquero y García-Argüelles, 2009; Morales y Oms, 2012). También debemos tener en cuenta la posibilidad de poseer períodos más antiguos que el Paleolítico Superior Final -c. 13600 cal вр-, aunque materialmente presenten poca visibilidad. Aun así, los primeros resultados obtenidos sobre los conjuntos tienden a comprender, en su mayoría, aspectos productivos típicos de cronologías pertenecientes entre el Epipaleolítico, el Neolítico y hasta el Campaniforme.

La obtención de un nivel más elevado de fiabilidad de acuerdo con la caracterización lítica de los conjuntos debe asociarse a la obtención de información de tales áreas de gran potencialidad arqueológica. Esta debe relacionarse con intervenciones que puedan identificar evidencias físicas in situ que permitan situar espaciotemporalmente las diferentes producciones líticas. De esta forma podrían relacionarse tanto los espacios como los conjuntos analizados. Todo esto nos permitiría obtener una comprensión global de las dinámicas sociales en estas áreas y su relación con los demás asentamientos arqueológicos conocidos en la región.

\section{Bibliografía}

Aggarwal, C. C. (2015): Data Mining. The Textbook. Berna: Springer. DOI: https://dx.doi. org/10.1007/978-3-319-14142-8

Alday, A. (2018): "Regions and Transferences in the Iberian Neolithic Path. The Case of the Lithic Projectiles”. Saguntum, 50, pp. 9-33. DOI: https://dx. doi.org/10.7203/SAGVNTVM.50.10856

Alday, A.; Montes, L. y Baldellou, M. (2012): "Cuenca del Ebro". En Rojo, M. A.; Garrido, R. y García, I. (coords.): El Neolítico en la Península Ibérica y su contexto europeo. Madrid: Editorial Cátedra, pp. 291-331.

Barandiarán, I. (1978): "El Abrigo de la Botiquería dels Moros. Mazaleón (Teruel). Excavaciones Arqueológicas de 1974", Cuadernos de Prehistoria y 
Arqueología Castellonense, 5, pp. 49-138. URL: https://hdl.handle.net/10234/45283

Barandiarán, I. y Cava, A. (2000): "A propósito de unas fechas del Bajo Aragón: Reflexiones sobre el Mesolítico y el Neolítico en la Cuenca del Ebro", Spal, 9, pp. 293-326. DoI: https://dx.doi.org/10.12795/ spal.2000.i9.16

Barton, C. M. (2013): "Stories of the past or science of the future? Archaeology and computational science". En Bevan, A. y Lake, M. (eds.): Computational Approaches to Archaeological Spaces. London: UCL Institute of Archaeology Publications, pp. 151-178.

Barton, C. M.; Bernabeu, J.; Aura, J. E. y García-PuCHOL, O. (1999): "Land-Use Dynamics and Socioeconomic Change: An Exemple from the Polop Alto Valley", American Antiquity, 64 (4), pp. 609-634. DoI: https://doi.org/10.2307/2694208

Barton, C. M.; Bernabeu, J.; Aura-Tortosa, J. E. y García-Puchol, O. (2002): "Dynamic landscapes, artifact taphonomy, and landuse modeling in the western Mediterranean", Geoarchaeology, 17, pp. 155-190.

Barton, C. M.; Bernabeu, J.; García-Puchol, O.; Schmich, S. y Molina-Balaguer, L. (2004): "Long-term socioecology and contingent landscapes", Journal of Archaeological Method and Theory, 11 (3), pp. 253-295.

BaYLIss, A. (2009): "Rolling out revolution: using radiocarbon dating in archaeology", Radiocarbon, 51 (1), pp. 123-147. DOI: https://doi.org/10.1017/ s0033822200033750

Bayliss, A.; Bronk Ramsey, C.; Van Der Plicht, J. y Whittle, A. (2007): "Bradshaw and Bayes: Towards a Timetable for the Neolithic", Cambridge Archaeological Journal, 17 (1), pp. 1-28. Dor: https://doi. org/10.1017/s0959774307000145

Bernabeu, J.; Barton, C. M. y Pérez Ripoll, M. (2001): "A taphonomic perspective on neolithic beginnings: theory, interpretation, and empirical data in the western Mediterranean", Journal of Archaeology Science, 28, pp. 597-612. Dor: https://doi. org/10.1006/jasc.2000.0591

Bernabeu, J.; García-Puchol, O.; la Roca Cervigón, N. y Barton, C. M. (1999): "Prospecciones sistemáticas en el Valle del Alcoi (Alicante): primeros resultados", Arqueología Espacial, 21, pp. 29-64.

Bernabeu, J.; Lozano, S. y Pardo-Gordó, S. (2017): "Iberian Neolithic Network: The rise and fall of the cardial world", Frontiers in Digital Humanities, 4 (7). DOI: https://doi.org/10.3389/fdigh.2017.00007
BINDER, D. (1987): Le Néolithique ancien provençal: technologie et typologie des outillages lithiques. Paris: CNRS.

Bordes, F. (1961): Typologie du Paléolithique ancien et moyen. París: CNRS.

Borrell, F. (2008): "La indústria lítica tallada del jaciment neolític de la Caserna de Sant Pau”, Quarhis, época II, 4, pp. 36-45.

Borrell, F. (2009): "La indústria lítica neolítica tallada en sílex de les mines 83, 84, 85 i 90 (Gavà, Baix Llobregat): morfologia i tecnología", Rubricatum, 4, pp. 109-124.

Bosch, J. (1993): "Cronologia prehistòrica al curs inferior de l'Ebre. Primeres datacions absolutes", Pyrenae, 24, pp. 53-56.

Bosch, J. (2000): "Les pràctiques funeràries durant el neolític al curs inferior de l'Ebre segons excavacions antigues". En Bosch, J.; Faura, J. M. y Villalbí, M. M.: Intervenció arqueológica a l'àrea del Molinàs (Amposta, Montsià): aproximació a les practiques funeràries $i$ al poblament des del neolitic fins a l'època andalusina a les terrasses de la zona de la desembocadura de l'Ebre. Tribuna d'Arqueologia, 2000-2001, pp. 8-13.

Bosch, J. (2011): "La Cueva del Vidre (Roquetes, Bajo Ebro). Asentamiento del Mesolítico y del Neolítico Antiguo en la Cordillera Costera Catalana meridional". En Gonçalves, V. S.; Diniz, M. y Sousa, A. C. (eds.): $5 .{ }^{\circ}$ Congresso do Neolitico Peninsular. Lisboa: Centro de Arqueologia da Univ. de Lisboa, pp. 182-188.

Bosch, J. (2016): "Epipaleolític i neolític antic a la serra del Caro: les coves de l'Hospital i del Vidre (Roquetes, Baix Ebre)”. En Martínez, J.; Diloli, J. y Villalbí, M. M. (coords.): Actes I Jornades d'Arqueologia de les Terres de l'Ebre. Tortosa: General. de Catalunya, vol. I, pp. 63-77.

Bosch, J.; Nadal, J.; Román, D. y Estrada, A. (2015): "Antiguas excavaciones, nuevas respuestas. El yacimiento epimagdaleniense de la Cova del Clot de l'Hospital (Roquetes, Baix Ebre)", Saguntum, 47, pp. 9-27. DOI: https://doi.org/10.7203/sagvntvm.47.3780

Bosch, J.; Villalbí, M. M. y Forcadell, A. (1996): “El Barranc d'en Fabra (Amposta, Montsià): un assentament neolític a l'aire lliure", Tribuna d'Arqueologia, 1994-1995, pp. 51-62.

BucK, C. y JuÁrez, M. (2017): Bayesian radiocarbon modelling for beginners. University of Sheffield. URL: https://arxiv.org/pdf/1704.07141.pdf (16-5-20)

Buck, C. E. y LitTon, C. D. (1991): "A computational Bayes approach to some common archaeological 
problems”. En Lockyear, K. y Rahtz, S. P. Q. (eds.): Computer Applications and Quantitative Methods in Archaeology. Oxford: Tempus Reparatum, pp. 93-99.

Buck, C. y SAHU, S. K. (2000): "Bayesian Models for relative archaeological chronology building", Journal of the Royal Statistical Society. Applied Statistics, 49 (4), pp. 423-440. DoI: https://doi.org/10.1111/14679876.00203

Esteve-GÁLVEZ, F. (1954): "Investigaciones arqueológicas en las terrazas cuaternarias del curso inferior del Ebro. Itinerario primero: de Amposta a la Carrova y Campredó", Noticiario Arqueológico Hispánico, III-IV, cuad. 1-3 (1954-1955), pp. 15-26.

Esteve-Gálvez, F. (1966): "La cueva sepulcral del Calvari d'Amposta", Pyrenae, 2, pp. 25-54.

Esteve-GÁLVez, F. (2000): Recerques arqueològiques a la Ribera Baixa de l'Ebre. I: Prehistòria. Tarragona: Museu del Montsià-Ajuntament d'Amposta.

Fernández-López de Pablo, J. (2006): "La producción lítica del IV y III milenio cal вC en el norte del País Valenciano: primeros datos sobre contextos habitacionales". En Bicho, N. y Verissimo, H. (eds.): Do Epipaleolítico ao Calcolitico na Península Iberica. Actas do IV congreso de Arqueología peninsular. Faro: Univ. do Algarve, pp. 263-277.

Fernández-López de Pablo, J. y Barton, M. (2013): "Bayesian Estimation Dating of Lithic Surface Collections", Journal of Archaeological Method and Theory, 22, pp. 559-583. DOI: https://doi. org/10.1007/s10816-013-9198-z

Forcadell, T. y Villalbí, M. M. (1999): “Cova Cervereta (Vinallop-Tortosa). Cavitat Sepulcral del calcolític-bronze antic al curs inferior de l'Ebre", Quaderns de Prehistòria i Arqueologia de Castelló, 20, pp. 37-54.

ForTEA, J. (1973): Los complejos microlaminares y geométricos del Epipaleolítico mediterráneo español. Salamanca: Univ. de Salamanca.

Gabarda, M. V. (ed.) (2010): El cingle de Mas Cremat (Portell de Morella, Castelló). Valencia: Ein Mediterraneo SL.

Gabarda, M. V.; Guillem, P. M.; De Haro, S.; Iborra, M. P.; Martínez, R.; Pérez, G.; Pérez, R.; Ruiz, J.; Ten, S. y Valcárcel, A. (2010): El Cingle del Mas Cremat (Portell de Morella, Castellón). Un asentamiento en altura con ocupaciones del Mesolitico Reciente al Neolitico Final. Valencia: Ein Mediterraneo sL. DoI: https://doi.org/10.13140/RG.2.1.1681.5448

García-Argüelles, P.; Nadal, J. y Fullola, J. M. (2002): "Vint anys d'excavacions a l'abric del Filador
(Margalef de Montsant, Priorat, Tarragona)", Tribuna d'Arqueologia, 1998-1999, pp. 71-96.

García-Argüelles, P.; Nadal, J. y Fullola, J. M. (2005): "El abrigo del Filador (Margalef de Montsant, Tarragona) y su contextualización cultural y cronológica en el Nordeste peninsular", Trabajos de Prehistoria, 62 (1), pp. 65-84. Dor: https://doi. org/10.3989/tp.2005.v62.11.56

García-Puchol, O. (2005): El proceso de neolitización en la fachada mediterránea de la peninsula Ibérica. Tecnología y tipología de la piedra tallada. Oxford: Archaeopress.

Genera, M. (1982): "Inventari arqueològic de la Ribera d'Ebre", Fonaments, 3, pp. 47-134.

Genera, M. (1984-1985): Memòria excavacions al Clot de l'Hospital (Roquetes). Memoria n. ${ }^{\circ}$ 328. Barcelona: Arxiu Servei d'Arqueologia.

Genera, M. (1991): L'Ebre final: del Paleolitic al món romà. Tortosa: Cooperativa Gràfica Dertosense.

Gibaja, J.; Palomo, A.; Francès, J. y Majó, T. (2006): "Les puntes de sageta de l'hipogeu calcolític del carrer París (Cerdanyola): caracterització tecnomorfològica i funcional", Cypsela, 16, pp. 127-133.

Gibaja, J. F.; Terradas, X.; Palomo, A. y Clop, X. (2010): "La indústria lítica del Iv/primera mitad II milenio cal BC en el Noreste de la Península Ibérica: contextos funerarios versus contextos domésticos", Munibe, 32, pp. 440-451.

Gironès, I.; PARdo-Gordó, S. y Molist, M. (2020): "La inferencia cronológica bayesiana aplicada a la industria lítica superficial procedente de las terrazas fluviales del Bajo Ebro (Aldover-Xerta, Baix Ebre)", Saguntum, 52, pp. 9-31.

Gómez, F.; Rey, A. y Royo, J. (1992): "Estudio de materiales del poblado Neolítico de Riols I (Mequinenza, Zaragoza). Campaña de 1990", Arqueología Aragonesa, 12, pp. 47-53.

Jover, F. J. (2011): "El instrumental lítico tallado de Benàmer: continuidad y ruptura en los procesos de producción lítica tallada entre el viI y el Iv milenio cal bC". En Torregrosa, P.; Jover, F. J. y López, E. (eds.): Benàmer (Muro de Alcoi, Alicante). Mesoliticos y Neoliticos en las tierras meridionales valencianas. Valencia: SIP, pp. 133-204.

Juan-Cabanilles, J. J. (2008): El utillaje de piedra tallada en la Prehistoria reciente valenciana. Aspectos tipológicos, estilisticos y evolutivos. Serie de Trabajos Varios, 109. Valencia: sip. 
Kunn, M. y Johnson, K. (2013): Applied Predictive Modelling. Berna: Springer. Dor: https://doi. org/10.1007/978-1-4614-6849-3

LAPLACE, G. (1974): La typologie analytique et structurale: base rationnelle d'étude des industries lithiques et osseuses. Marseille: CNRS, pp. 91-143.

Martí, B.; Aura, J. E.; Juan Cabanilles, J.; García Puchol, O. y Fernández López de Pablo, J. (2009): "El Mesolítico geométrico de tipo Cocina en el País Valenciano”. En Utrilla, P. y Montes, L. (eds.): El Mesolítico Geométrico en la Peninsula Ibérica. Monografías Arqueológicas, 44. Zaragoza: Univ. de Zaragoza, pp. 205-258.

Martí, M.; Pou, R. y Carlús, X. (1997): Excavacions arqueologiques a la Ronda sud de Granollers, 1994. La necròpolis del Neolitic Mitjà i les restes romanes del Cami de Can Grau (La Roca del Vallès, Vallès Oriental) $i$ els jacimients de Cal Jardiner (Granollers, Vallés Oriental). Barcelona: Generalitat de Catalunya.

Martín, A. y Miret i Mestre, J. (1990): “Un enterrament neolític als Garrofers del Torrent de Santa María (Vilanova i la Geltrú, Garraf) dins el seu context cultural i cronològic", Cypsela, viII, pp. 49-60.

Mazo, E. y Montes, L. (1992): "La transición Epipaleolítico-Neolítico antiguo en el yacimiento de El Pontet (Maella, Zaragoza)". En Utrilla, P. (coord.): Aragón/Litoral Mediterráneo. Intercambios culturales durante la Prehistoria. Zaragoza: Instit. Fernando el Católico, pp. 243-254.

Merino, J. (1994): Tipologia Litica. San Sebastián: Soc. de Ciencias Aranzadi.

Mestres, J. (1987): "La indústria lítica en sílex del Neolític antic de les Guixeres de Vilobí", Olerdulae, XII (1-4), pp. 5-72.

Miró, J.; Molist, M. y Vilardell, R. (1992): “Aportaciones al estudio del Neolítico antiguo en la Cataluña meridional, partiendo de la industria lítica del yacimiento al aire libre de la Timba del Bareny (Riudoms, Tarragona)". En Utrilla, P. (coord.): Aragón/ Litoral Mediterráneo. Intercambios culturales durante la Prehistoria. Zaragoza: Instit. Fernando el Católico, pp. 345-359.

Miró I Miró, J. M. (1994): La cronología dels estils ceràmics neolitics a Catalunya $i$ la datació de C14 de la Timba del Barenys (Riudoms, Tarragona). Tarragona: Univ. Rovira i Virgili.

Molist, M; Gómez, A.; Alcántara, R.; Arnaiz, R.; Bofill, M. y Reverté, A. (2016a): "Les ocupacions prehistòriques a les Coves de l'Aumediella (Benifallet): una visió sintética”. En Martínez, J.; Diloli,
J. y Villalbí, M. M. (coords.): Actes I Jornades d'Arqueologia de les Terres de l'Ebre. Tortosa: Generalitat de Catalunya, vol. I, pp. 78-89.

Molist, M.; Gómez, A.; Borrell, F.; Ríos, P. y Bosch, J. (2016b): "El 'Chassense' y los 'Sepulcres de Fossa de Cataluña': relaciones complejas entre culturas arqueológicas vecinas". En Perrin, T.; Champon, P.; Gibaja, J. F. y Goude, G. (dirs.): Le Chasséen, des Chasséens... Retour sur une culture nationale et ses parallèles, Sepulcres de Fossa, Cortaillod, Lagozza. Actes Colloque International de Paris (2014). Toulouse: Archives d'Écologie Préhistorique, pp. 143-157.

Morales, J. I. y OMs, X. (2012): "Las últimas evidencias mesolíticas del NE peninsular y el vacío Pre-Neolítico", Rubricatum. Revista del Museu de Gavà, 5, pp. 35-41.

Ortman, S. G. (2016): "Uniform Probability Density Analysis and Population History in the Northern Rio Grande", Journal of Archaeological Method and Theory, 23, pp. 95-126. Dor: https://doi.org/10.1007/ s10816-014-9227-6

Ortman, S. G.; Varien, M. D. y Gripp, T. L. (2007): "Empirical Bayesian methods for archaeological survey data: an applications from the Mesa Verde region", American Antiquity, 72 (2), pp. 241-272. DoI: https://doi.org/10.2307/40035813

Otárola-Castillo, E. y Torquato, M. G. (2018): "Bayesian Statistics in Archaeology", Annual Review of Anthropology, 47, pp. 435-453. Dor: https://doi. org/10.1146/annurev-anthro-102317-045834

Palomo, A. y Gibaja, J. F. (2002): “Análisis de las puntas del sepulcro calcolítico de la Costa de Can Martorell (Dosrius, El Maresme)". En Clemente, I.; Risch, R. y Gibaja, J. F. (eds.): Análisis funcional. Su aplicación al estudio de sociedades prehistóricas. BAR Intern. Ser., 1073. Oxford: Archaeopress, pp. 243-249.

Palomo, A.; Gibaja, J. F.; Ortega, D.; Alonso, N.; Marín, D. y Moya, A. (2012): "La industria lítica tallada del asentamiento de Minferri (Juneda, Lleida) a finales del III/primera mitad del II milenio cal. BC", Cypsela, 19, pp. 103-122.

Pardo-Gordó, S.; Diez-Castillo, A. y Bernabeu, J. (2009): "Áreas y suelos: El tamaño de los yacimientos de superficie. Una propuesta metodológica”, Spal, 18 pp. 41-53.

Pardo-Gordó, S.; Diez-Castillo, A.; Bernabeu, J.; Chaos, V.; Molina-Balaguer, L. y Barton, C. M. (2015): "Prospecciones sistemáticas en la depressió de l'Alcoi (Alacant): analizando las colecciones superficiales". En GonçaLves, V. S. (ed.): 5. Congresso do 
Neolitico Peninsular. Lisboa: Centro de Arqueologia da Univ. de Lisboa, pp. 497-404.

Piera, M.; Gómez, A.; Molist, M.; Ríos, P. y AlcánTARA, R. (2016): "El tram baix de l'Ebre a les èpoques del Neolític i Bronze inicial: Aportacions al seu coneixement a partir de l'assentament del Molló (Móra la Nova)". En Martínez, J.; Diloli, J. y Villalbí, M. (coords.): Actes I Jornades d'Arqueologia de les Terres de l'Ebre. Tortosa: General. de Catalunya, vol. I, pp. 90-103.

Robertson, I. G. (1999): "Spatial and Multivariate Analysis, Random Sampling Error, and Analytical Noise: Empirical Bayesian Methods at Teotihuacán, Mexico", American Antiquity, 64, pp. 137-152. Dor: https://doi.org/10.2307/2694350

Rodanés, J. M.; Tilo, M. A. y Ramón, N. (1996): El Abrigo de Els Secans (Mazaleón, Teruel). La ocupación del Valle del Matarraña durante el Epipaleolitico y el Neolitico Antiguo. Al-Qannis, 6. Boletín del Taller de Arqueología de Alcañiz. Alcañiz: Taller de Arqueología de Alcańiz. DoI: https://doi. org/10.13140/2.1.3573.7606

Royo, J. I. y Gómez, F. (1992): "Riols I: Un asentamiento neolítico al aire libre en la confluencia de los ríos Segre y Ebro". En Utrilla, P. (coord.): Aragón/ Litoral Mediterráneo. Intercambios culturales durante la Prehistoria. Zaragoza: Instit. Fernando el Católico, pp. 297-308.

Snitker, G.; Diez-Castillo, A.; Barton, C. M.; Bernabeu, J.; García-Puchol, O. y Pardo-Gordó, S. (2018): "Patch-based survey methods for studying prehistoric human land-use in agriculturally modified landscapes: A case study from the Canal de Navarrés, eastern Spain", Quaternary International, 483, pp. 5-22. Dor: https://doi.org/10.1016/j. quaint.2018.01.034
Soriano, I.; Martínez, P.; Labaune, M.; Cattin, F. y Oliart, C. (2016): “60 anys després de la Cova del Calvari (Amposta, Montsià). Revisió en curs i aportació de noves dades analítiques al Campaniforme del nord-est de la Península Ibèrica”. En Martínez, J.; Diloli, J. y Villalbí, M. (coords.): Actes I Jornades d'Arqueologia de les Terres de l'Ebre. Tortosa: Generalitat de Catalunya, vol. I, pp. 104-115.

Soto, A.; Alday, A.; Mangado, X. y Montes, L. (2016): "Epipaleolítico y Mesolítico en la vertiente sur de los Pirineos desde la perspectiva de la industria lítica”, Munibe Antropologia-Arkeologia, 67, pp. 295312. DOI: https://doi.org/10.21630/maa.2016.67. mis01

Thoeming, A. (2016): "Dealing with Data: Naïve Bayesian Classification and a Case Study from Viking Age Sweden", International Journal of Student Research in Archaeology, 1 (1), pp. 193-204.

Utrilla, P. y Mazo, C. (2014): La Peña de las Forcas (Graus, Huesca): un asentamiento estratégico en la confluencia del Esera y el Isábena. Monografías Arqueológicas/Prehistoria, 46. Zaragoza: Univ. de Zaragoza.

Vaquero, M. y García-Argüelles, P. (2009): “Algunas reflexiones sobre la ausencia de Mesolítico Geométrico en Cataluña”. En Utrilla, P. y MonTES, L. (eds.): El Mesolítico Geométrico en la Península Ibérica. Monografías Arqueológicas, 44. Zaragoza: Univ. de Zaragoza, pp. 191-203.

Vilaseca, S. (1936): La indústria del silex a Catalunya. Les estacions tallers del Priorat $i$ Extensions. Reus.

Vilaseca, S. (1939): “Dos cuevas prehistóricas de Tivissa (provincia de Tarragona)", Ampurias, I, pp. 159-185.

Vilaseca, S. (1953): Las industrias del sílex tarraconense. Madrid: CSIC.

Vilaseca, S. (1973): Reus y su entorno en la Prehistoria. Reus: Asociación de Estudios Reusenses. 